\title{
The Role of Gravity Wave Breaking in a Case of Upper-Level Near-Cloud Turbulence
}

\author{
DRAGANA ZOVKO-RAJAK \\ School of Earth Sciences, University of Melbourne, and Bureau of Meteorology, Melbourne, Australia \\ TODD P. LANE \\ School of Earth Sciences, and ARC Centre of Excellence for Climate Extremes, University of Melbourne, \\ Melbourne, Australia
}

Robert D. SHARMAN AND STANLEy B. TRIER

National Center for Atmospheric Research, Boulder, Colorado

(Manuscript received 18 December 2018, in final form 15 July 2019)

\begin{abstract}
An observed turbulence encounter that occurred outside a mesoscale convective system over the central United States on 3 June 2005 is investigated using observations and high-resolution numerical modeling. Here, the mechanisms associated with the observed moderate-to-severe turbulence during the evolution of this convective system are examined. Comparison between aircraft-observed eddy dissipation rate data with satellite and radar shows that a majority of turbulence reports are located on the south side and outside of a nocturnal mesoscale convective system (MCS), relatively large distances from the active convective regions. Simulations show that divergent storm-induced upper-level outflow reduces the environmental flow on the south side of the MCS, while on the north and northwest side it enhances the environmental flow. This upperlevel storm outflow enhances the vertical shear near the flight levels and contributes to mesoscale reductions in Richardson number to values that support turbulence. In addition to the role of the MCS-induced outflow, high-resolution simulations (1.1-km horizontal grid spacing) show that turbulence is largely associated with a large-amplitude gravity wave generated by the convective system, which propagates away from it. As the wave propagates in the region with enhanced vertical shear caused by the storm-induced upper-level outflow, it amplifies, overturns, and breaks down into turbulence. The location of the simulated turbulence relative to the storm agrees with the observations and the analysis herein provides insight into the key processes underlying this event.
\end{abstract}

\section{Introduction}

Deep convective clouds are an important source of turbulence that affect aviation. In a climatological study of upper-level $(5.5-18.3 \mathrm{~km})$ turbulence over the contiguous United States, Wolff and Sharman (2008) found that approximately $20 \%$ of moderate-or-greater turbulence reports are associated with deep convection. Yet, the importance of turbulence associated with convection varies regionally. In their study of characteristics of aviation turbulence over South Korea, Kim and Chun (2011) found that only $11 \%$ of moderate or greater

Corresponding author: Dragana Zovko-Rajak, dragana.rajak@ bom.gov.au turbulence events were associated with convection. Regardless of its regional variation, turbulence generated by convection is an important hazard for aviation, and there are still gaps in our understanding of its generation mechanisms. This study focuses on understanding the mechanisms responsible for an encounter between a commercial aircraft and severe turbulence outside of a mesoscale convective system.

Turbulence generated by deep convection occurs inside the cloud but also in the clear air above and around the cloud (Lester 1994). In-cloud convectively induced turbulence (CIT) could be avoided by detecting cloud boundaries through onboard or ground-based radar and satellite imagery, and by evading cloudy air. However, CIT that occurs in the clear air outside of cloud [or near-cloud 
turbulence (NCT)] is more difficult to avoid as it is invisible and difficult to detect using standard onboard or ground-based radars (Williams et al. 2006) and may extend large distances from the convection that generated it. Lane and Sharman (2014) examined the relative intensity of turbulence within and surrounding an idealized thunderstorm. This study found that regions of turbulence that extend more than $50 \mathrm{~km}$ away from the cloud boundary (horizontally) and more than $5 \mathrm{~km}$ above the storm are more turbulent than some locations within the storm itself. The importance of NCT has long been appreciated (e.g., Prophet 1970; Pantley and Lester 1990; Kaplan et al. 2005) and recent advances in computing power and high-resolution numerical modeling coupled with improvements in reporting of turbulence (Lane et al. 2012) enabled significant progress in the understanding of the mechanisms behind the complicated NCT phenomenon. However, there are still a number of issues regarding the dynamics and prediction of NCT that need to be solved. Additionally, resolving aircraft-scale turbulence (horizontal scales of order $100 \mathrm{~m}-2 \mathrm{~km}$ ) still remains a challenging computational problem.

Lane et al. (2012) reviewed sources and examples of NCT, which includes turbulence generated above deep convection as well as turbulence generated adjacent to and large distances from moist convection. Of the many sources associated with above-cloud NCT, breaking of gravity waves that are generated by the overshooting updrafts is the most important one (e.g., Lane et al. 2003; Lane and Sharman 2006, 2008). The breakdown of convectively generated gravity waves has been attributed to the interaction between the gravity waves and a critical level caused by a combination of background wind shear and cloud-induced wind perturbations. Cloud-induced flow deformation and enhanced wind shears at the uppermost boundary of overshooting convective updrafts can also lead to turbulence (e.g., Grabowski and Clark 1991; Lane et al. 2003) by supporting Kelvin-Helmholtz $(\mathrm{KH})$ instability. Additionally, turbulence can also occur above dissipating convection through the production of horizontal vorticity and horizontal buoyancy gradients across the cloud boundary, which lead to turbulence and vertical mixing (Kim and Chun 2012).

Other cases summarized by Lane et al. (2012) showed that regions large distances (tens to several hundreds of kilometers) from active thunderstorms are also conducive to NCT (e.g., Fovell et al. 2007; Trier and Sharman 2009, 2016). In one case, storm-induced upper-level outflow modifies the surrounding environment by causing both a decrease in stability and an increase in vertical shear, which leads to localized reductions in Richardson number (Ri) and susceptibility to turbulence in the clear air to the southeast of the storm (Fovell et al. 2007). Additionally, horizontally propagating gravity waves that emanate from the storm can be ducted by the high shears below the tropopause and perturb cloud environments that are already near the turbulence production threshold (i.e., low background $\mathrm{Ri}$ ). These cases highlighted the importance of NCT adjacent to organized convection as an important turbulence hazard, especially because of its occurrence large distances from the detectable cloud boundary. The case considered herein is focused on an encounter that occurred about $50 \mathrm{~km}$ to the south of an organized mesoscale convective system.

A number of recent studies have examined the mechanisms underlying turbulence adjacent to convection. Trier and Sharman (2009) used convectionpermitting simulations to analyze a case study where turbulence occurred several hundred kilometers from the thunderstorm region of an active mesoscale convective system (MCS). For this case they showed that turbulence generation was prevalent on the north side of the MCS due to enhanced vertical shear and small static stability, contributing to reduced $\mathrm{Ri}$ within the MCS-induced upper-level outflow. A higher-resolution modeling study of this same event (Trier et al. 2010) documented the evolution of radial cloud bands within the MCS upper-level outflow, which coincide with the observed turbulence, with their orientation influenced by the vertical shear in the MCS outflow. Turbulence is often observed in the vicinity of these transverse bands associated with MCS anvils (Lenz et al. 2009) but also in tropical cyclone outflows and jet stream cirrus of midlatitude cyclones (Knox et al. 2010). A recent study by Kim et al. (2014) investigated generation mechanisms for moderate and severe turbulence that was encountered within or just above the cirrus anvil that was associated with an oceanic cyclone off the east coast of Japan. In this study, turbulence events occurred near the southern edge of the cirrus bands that arose from convection associated with a larger-scale oceanic cyclone. They found that the generation of NCT in the vicinity of cirrus bands was due to the strong synoptic-scale vertical shear within the anvil cloud layer that led to flow deformations and mixing near the cloud top, resulting in localized turbulence. They also noted that more studies of cirrus bands in different weather regimes (e.g., anticyclonic jet streams and upper-level outflows of midlatitude cyclones) are necessary to understand the generation mechanisms behind cirrus bands and NCT events.

While the majority of NCT cases are associated with the midlatitude warm-season convection, it can occur during the cold season as well. Trier et al. (2012) 
examined a cold-season case where turbulence occurred within a deep synoptic cyclone but was laterally displaced from moist convection and occurred at a higher altitude. They showed that two clusters of NCT were mainly associated with convectively induced upper-level outflow similar to those in warm-season MCSs (e.g., Trier and Sharman 2009). The northern cluster of moderate-or-greater turbulence in Trier et al. (2012) is associated with $\mathrm{KH}$ instability caused by a strong anticyclonic outflow and the associated enhanced vertical shear above the jet. In their southern region of moderate-or-greater turbulence, vertically propagating gravity waves excited by shallower moist convection amplified and broke in some locations above the convection, leading to turbulence. In other locations, these waves indirectly led to turbulence by helping excite $\mathrm{KH}$ instability within layers of the strongest vertical shear above them, which, itself, was enhanced by the upperlevel convective outflow.

Shear $(\mathrm{KH})$ instabilities caused by the storm-induced upper-level outflow are also important in generating turbulence downstream of the convective regions of storms (Zovko-Rajak and Lane 2014). In their idealized supercell study, turbulence was primarily associated with a strong storm-induced upper-level outflow jet centered near the tropopause, with strong shear below and above the jet creating regions of $\mathrm{Ri}<0.25$ and $\mathrm{KH}$ instability. This turbulence extended more than $100 \mathrm{~km}$ away from the main convective regions, in both clear air surrounding the convection and within cirrus. Additionally, this study showed that shear instability generates small-scale gravity waves that are coincident with the regions of turbulence and are trapped within the jet.

The aforementioned studies show that circulations originating in the region surrounding thunderstorms can create conditions that are conducive to turbulence. This involves a combination of mechanisms related to convection that are often difficult to isolate. These mechanisms include: Kelvin-Helmholtz instabilities caused by convectively induced shear enhancements, thermodynamic and dynamic mesoscale destabilization by upper-storm outflows, gravity wave breaking, and localized shear enhancements by gravity waves in mesoscale regions of low Richardson number. Therefore, the main aim of this study is to further improve our understanding of mechanisms that lead to the generation of NCT around deep convection, specifically turbulence generated remotely from active convection. Here, a case study of actual aircraft turbulence encounters that occurred in the clear air outside a convective system over the central United States is examined using observations and convection-permitting simulations. This paper examines an event that occurred at approximately 0300 UTC 3 June 2005, where severe turbulence occurred about $50 \mathrm{~km}$ to the south of a MCS; it will be shown that this turbulence was likely caused by breaking gravity waves that interacted with a mesoscale region that was already destabilized by the storm outflow.

The remainder of this paper is organized as follows. Section 2 presents an overview of the reported turbulence and large-scale environmental flow for the 0300 UTC 3 June 2005 event that is based on the operational model analysis. Section 3 describes the numerical model and experiment design. Results from the simulations are discussed in section 4 , with a summary in section 5 .

\section{Observations of the 3 June 2005 (0300 UTC) turbulence case}

\section{a. In situ turbulence reports}

This study investigates a case on 3 June 2005 where turbulence occurred in the clear air outside of a mesoscale convective system (MCS) over the U.S. Great Plains. This event was identified using the aircraftobserved atmospheric eddy dissipation rate (EDR); radar and satellite imagery helped determine the location of NCT relative to the convective system. EDR is an aircraft-independent turbulence metric that is calculated from automated in situ turbulence detection systems (Cornman et al. 1995; Sharman et al. 2014) and is very useful for case studies of NCT as it has a 1-min temporal sampling interval ( $\sim 10 \mathrm{~km}$ horizontal) (e.g., Lane et al. 2012) providing regular and objective atmospheric turbulence observations. EDR measurements are superior to pilot reports (PIREPS) for identifying NCT cases because of the good spatial and temporal accuracy compared to PIREPS, and therefore their utility to determine whether an event is inside or outside of cloud.

Figure 1 shows EDR data (colored dots) from several commercial airliners superposed on the 0325 UTC 3 June 2005 Geostationary Operational Environmental Satellite-12 (GOES-12) infrared satellite image. The shown reports are for times between 0255 and 0355 UTC, and for aircraft altitudes greater than $20000 \mathrm{ft}$ (greater than $6 \mathrm{~km}$ ). Each dot represents a maximum EDR value during the 1-min sampling interval, where green represents EDR values $\varepsilon^{1 / 3} \leq 0.14$, yellow $0.14<\varepsilon^{1 / 3} \leq 0.34$, orange $0.34<\varepsilon^{1 / 3} \leq 0.54$, and red $\varepsilon^{1 / 3}>0.54 \mathrm{~m}^{2 / 3} \mathrm{~s}^{-1}$, approximately indicating subjective categories of smooth, light, moderate and severe turbulence intensities, respectively. These thresholds are different than the current International Civil Aviation Organization (2007) thresholds that are $0.10,0.40$, and $0.70 \mathrm{~m}^{2 / 3} \mathrm{~s}^{-1}$ for light, moderate, and severe turbulence intensities, respectively. 




FIG. 1. EDR $\left(\varepsilon^{1 / 3}\right)$ turbulence measurements from several commercial aircraft superposed on a 0325 UTC 3 Jun 2005 Geostationary Operational Environmental Satellite-12 (GOES-12) infrared satellite image. Each dot represents a maximum EDR value during 1-min sampling interval, where green represents EDR values $\varepsilon^{1 / 3} \leq 0.14$, yellow $0.14<\varepsilon^{1 / 3} \leq 0.34$, orange $0.34<\varepsilon^{1 / 3} \leq 0.54$, and red $\varepsilon^{1 / 3}>0.54 \mathrm{~m}^{2 / 3} \mathrm{~s}^{-1}$, indicating smooth, light, moderate, and severe turbulence intensities, respectively. These reports are for times between 0255 and 0355 UTC, and for altitudes greater than $20000 \mathrm{ft}$. The reports are limited by the geographic locations and as a result are truncated at Colorado and New Mexico western borders.

However, Sharman et al. (2014) identify a slightly different range of $\varepsilon^{1 / 3}$ values, based on comparison to PIREPS, which are more consistent with those used here.

Continuous light and moderate to severe turbulence was reported in western Kansas from 0315 to 0327 UTC (Fig. 1), with a severe EDR report at 0319 UTC at a flight level of $\sim 38000 \mathrm{ft}$; noting that this flight level should not be interpreted as a geometric height, but instead refers to the altitude of the flight-level pressure as defined by the U.S. Standard Atmosphere, 1976 (Lane et al. 2003; Sharman et al. 2006; Trier and Sharman 2009). Based on the model data that are described in section 3, at this time and location a flight level of $38000 \mathrm{ft}$ corresponds to an actual height of $11.9 \mathrm{~km}$ ASL (above sea level). This turbulence event occurred on the southern side of an MCS, which is depicted by the composite radar reflectivity at 0317 UTC (Fig. 2). From the composite reflectivity and the satellite image it is evident that the encountered turbulence is located in the clear air to the south of the main convective region of the storm. The severe report is about $50 \mathrm{~km}$ from the satellite detected cloud boundary and therefore this is considered an NCT event. The mechanisms that generate turbulence in this case are investigated in subsequent sections in more detail.

\section{b. Large-scale environmental flow}

Upper-air Rapid Update Cycle (RUC; Benjamin et al. 2004) analyses (Figs. 3a,b) show a large, curved upper-level trough that extends over Montana and southwest Canada, and a southwesterly jet stream just ahead of it. This jet stream extends through the U.S. West and Midwest, with maximum winds over Wyoming at 0000 UTC (Fig. 3a) moving over the Dakotas $3 \mathrm{~h}$ later (Fig. 3b). This upper-level trough coincides with a large surface low pressure system that is located over the northernmost part of the United States and western Canada (Figs. 4a,b).

A cold front extends northeast from this system and bends southward into the stationary front over the Dakotas; which extends farther across Nebraska and central Colorado into Utah and Nevada. Another smaller low pressure system is located over the southeastern border of Colorado.

Surface temperature (Figs. 4a,b) shows a clear boundary between the cold, polar air that is coming from the north and the warm, humid air that is coming from the southeast; marking the location of the stationary front. Conditions for deep convection are favored here due to warm, moist air originating from the south of the stationary front and a squall line starts to form along the stationary front. By 0300 UTC (local time is UTC $-6 \mathrm{~h}$ ) a squall line is well developed (Fig. 1) and moves ahead of the front in the southeast direction.

At this the stage the majority of stratiform precipitation is found behind and to the northwest of active convective cells (cf. Fig. 2). This squall line resembles the traditional squall line archetype, with trailing stratiform regions (e.g., Fujita 1955; Houze 1989), which occurs over the central United States during the warm season (May-August) and together with other types of MCSs contributes to the majority of rain in the central Great Plains and U.S. Midwest (e.g., Fritsch et al. 1986; Carbone et al. 2002; Trier et al. 2006).

The vertical structure of the atmosphere at the location close to the severe EDR report (Fig. $1,38.38^{\circ} \mathrm{N}$, $100.89^{\circ} \mathrm{W}$ ) is analyzed in Fig. 5. These profiles were calculated from the RUC analysis and show soundings prior to the event at 0000 UTC (Fig. 5a) and near the time of the turbulence report at 0300 UTC (Fig. 5b). The environment is characterized by a moist and well-mixed layer up to $\sim 700 \mathrm{hPa}$ that is separated by a capping inversion from the dry layer above. Between 0000 and 0300 UTC the low-level nocturnal inversion has developed and the tropopause is located at $z \sim 12 \mathrm{~km}$. This type of sounding is characteristic for the U.S. Great Plains during spring. The wind profile shows a strong upper-level southwesterly jet that is centered near $z \sim 12 \mathrm{~km}$ at 0000 and at 0300 UTC.

The storm's influence on turbulence generation around the time of the EDR reports is investigated 


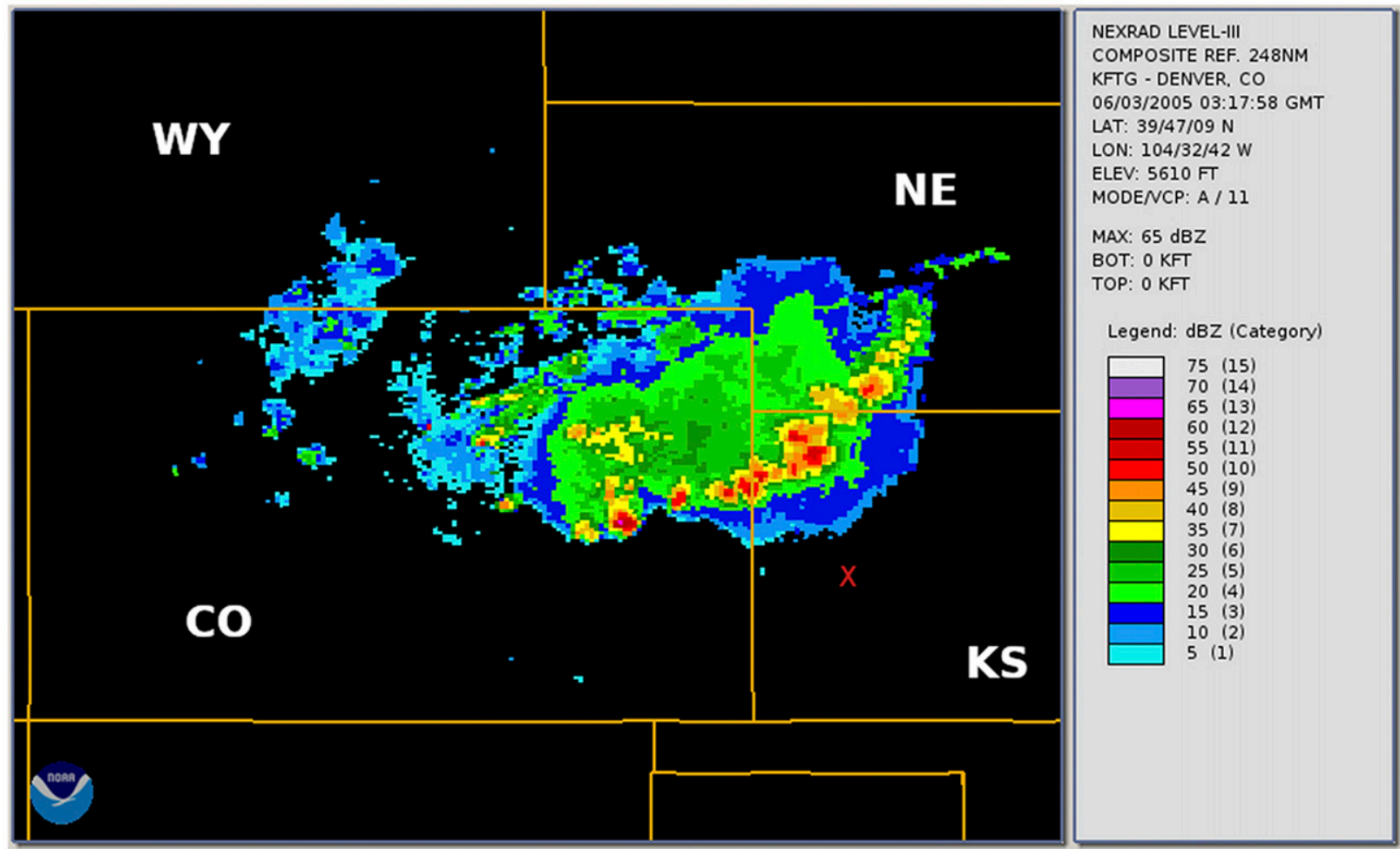

FIG. 2. WSR-88D NEXRAD Level III radar composite reflectivity at 0317 UTC 3 Jun 2005. The location of the severe EDR report is marked by the red cross.

below; during this time the convective line is evolving into a mature MCS. As mentioned previously, the EDR reports are located on the south side of the squall line and in the clear air about $\sim 50 \mathrm{~km}$ outside of the convective system. Additional weaker reports are found to the north of the storm, and these are discussed briefly later in section 4 .

\section{Numerical model and experiment design}

\section{a. Numerical model}

All simulations presented here are conducted using the Weather Research and Forecasting (WRF) Model, version 3.3.1. This model features fully compressible Euler nonhydrostatic equations, solved using a massbased, terrain-following vertical coordinate and a thirdorder Runge-Kutta time integration scheme. The model uses Arakawa $\mathrm{C}$ grid staggering and the vertical grid spacing can vary with height. A detailed description of the model can be found in Skamarock et al. (2008). The WRF Model has been used successfully for highresolution modeling of observed turbulence cases in several previous studies (e.g., Trier and Sharman 2009, 2016; Trier et al. 2012; Kim and Chun 2010, 2012) as well as in idealized simulations (Zovko-Rajak and Lane 2014).
For the current study the model consists of four twoway nested domains with horizontal grid spacings of 30 (D1), 10 (D2), 3.3 (D3), and 1.1 (D4) km, respectively (Fig. 6). All domains have 121 vertical grid points with spacing less than $\sim 200 \mathrm{~m}$ below $14 \mathrm{~km}$ (being finest near the surface) and then increasing to $\sim 900 \mathrm{~m}$ near the model top at $\sim 26.4 \mathrm{~km}(20 \mathrm{hPa})$.

A Rayleigh damping (sponge) layer applied in the top $8 \mathrm{~km}$ of the model mitigates reflection of the vertically propagating gravity waves off the upper boundary. The initial and boundary conditions are obtained from the 6-hourly National Centers for Environmental Prediction (NCEP) Global Forecast System (GFS) analyses.

The simulations discussed in this paper use the Thompson et al. (2008) microphysics scheme, while other parameterizations include the Rapid Radiative Transfer Model (RRTM) longwave (Mlawer et al. 1997) and the Goddard (Chou and Suarez 1994) shortwave radiation schemes, and the Noah land surface model (Ek et al. 2003). The Kain-Fritsch cumulus scheme (Kain 2004) is used on the outer two domains, D1 and D2, only. The Mellor-Yamada-Janjić (MYJ) planetary boundary layer (PBL) scheme was used for parameterization of turbulence in the PBL and in the free atmosphere (Janjić 2002). The MYJ scheme determines eddy diffusion 


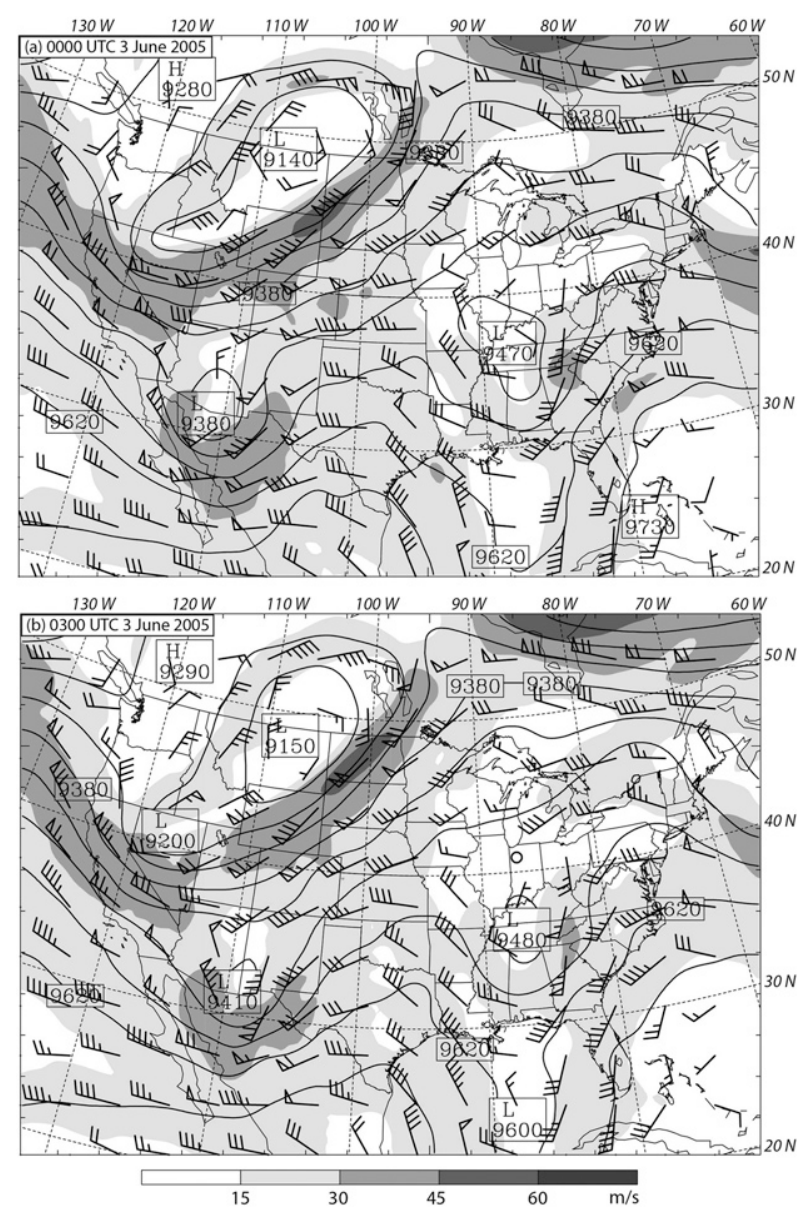

FIG. 3. RUC 300-hPa map valid at (a) 0000 and (b) 0300 UTC 3 Jun 2005. Black contours represent geopotential height ( $\mathrm{m}$, contour interval is $40 \mathrm{~m}$ ) superimposed on horizontal winds (shading and wind barbs). Barbed symbols represent horizontal winds using the standard meteorological plotting convention (half barb $=5 \mathrm{kt}$, full barb $=10 \mathrm{kt}$, flag $=50 \mathrm{kt} ; 1 \mathrm{kt} \approx 0.5144 \mathrm{~m} \mathrm{~s}^{-1}$ ).

coefficients from prognostically calculated turbulence kinetic energy (TKE). Other experiments were also conducted that used different microphysics schemes (not shown). It was found that these experiments did not produce a convective system that compares as well with the observations as those presented herein.

\section{b. Simulations}

The simulation that is conducted to analyze the 0300 UTC turbulence event (section 2) is named hereafter CTRL1 simulation; it uses a full set of physical parameterizations and model domains that are outlined above. The CTRL1 simulation was integrated from 1200 UTC 2 June to 1200 UTC 3 June 2005. To investigate the influence of deep moist convection on upper-level flow and vertical shear near the turbulence encounter, another simulation (hereafter NOLH1) was

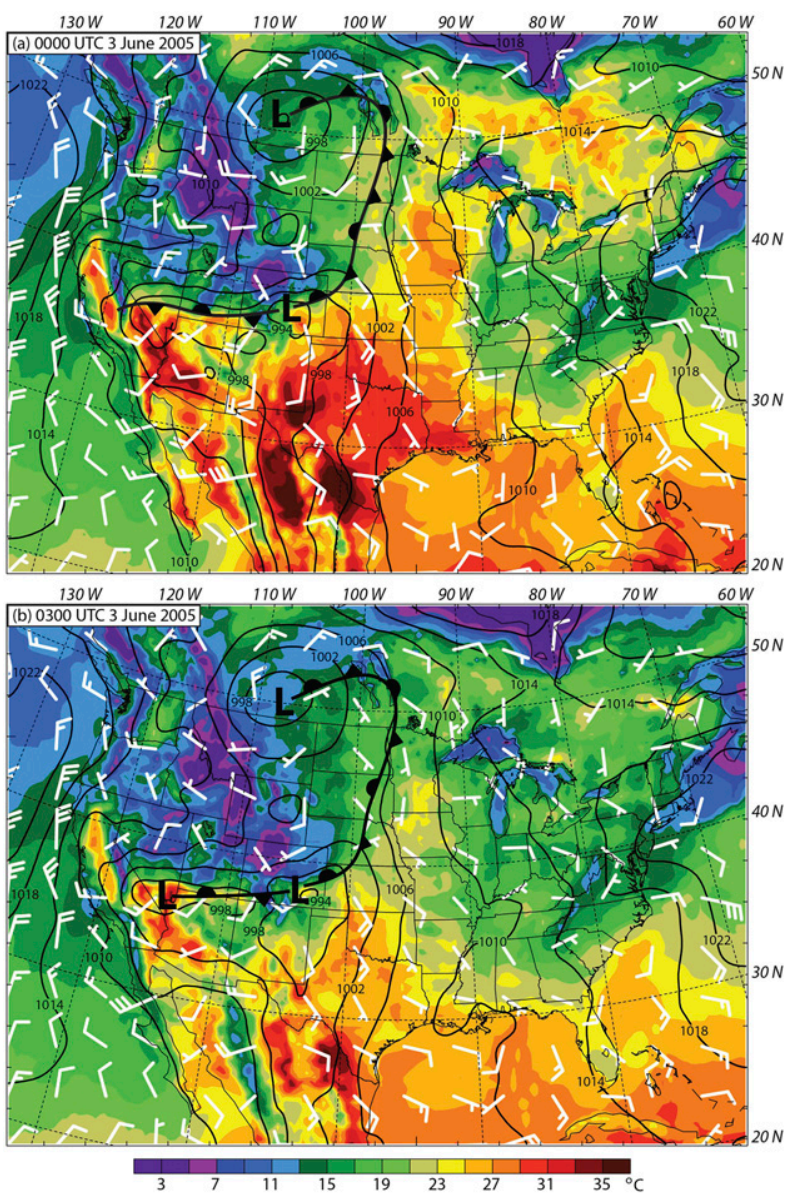

FIG. 4. RUC surface map valid at (a) 0000 and (b) 0300 UTC 3 Jun 2005. Blue contours represent mean sea level pressure (hPa, contour interval is $4 \mathrm{hPa}$ ), shaded contours represent surface temperature $\left({ }^{\circ} \mathrm{C}\right)$ and barbed symbols represent horizontal winds using the standard meteorological plotting convention (half barb $=5 \mathrm{kt}$, full barb $=10 \mathrm{kt}$, flag $=50 \mathrm{kt} ; 1 \mathrm{kt} \approx 0.5144 \mathrm{~m} \mathrm{~s}^{-1}$ ).

performed that was identical to CTRL1 except that latent heating from microphysics was disabled and it consists of only 3 domains (D1, D2, D3 in Fig. 6), with the innermost domain having $3.3 \mathrm{~km}$ horizontal grid spacing. Latent heating was disabled approximately $6 \mathrm{~h}$ before the turbulence event at 2100 UTC 2 June 2005 (prior to this time the full suite of model physics parameterizations were used). This 6-h interval prevents spurious gravity wave activity from influencing comparisons between CTRL1 and NOLH1, which might otherwise result from abrupt disabling of latent heating.

For comparison between the RUC data and WRF simulations (section $4 \mathrm{a}$ ) the output from the $10 \mathrm{-km}$ domain (D2) is used, while for comparison between NOLH1 and CTRL1 simulation output from the $3.3-\mathrm{km}$ domain D3 is used (section 4b). In all other analyses output from the 1.1-km domain (D4) is used. 

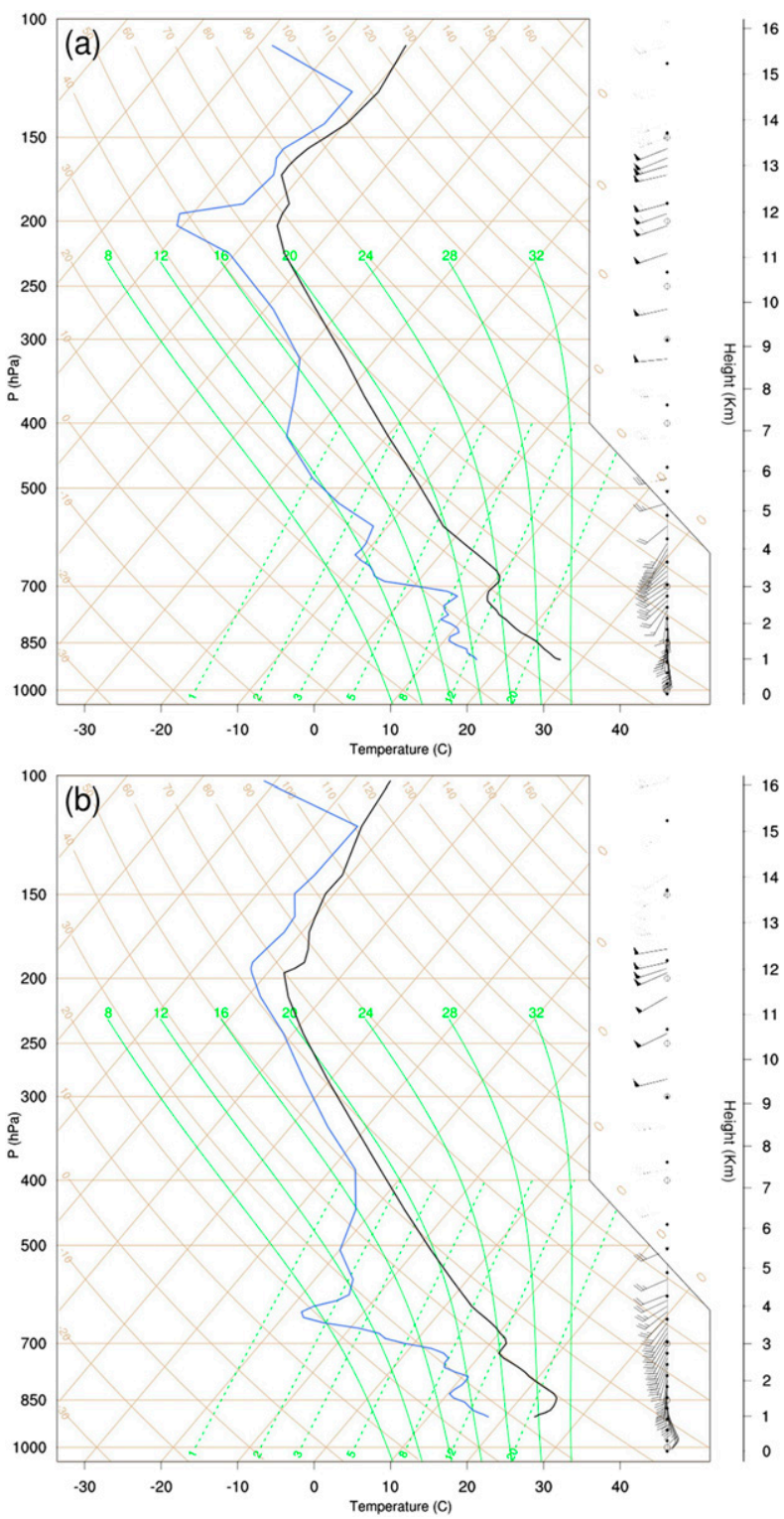

FIG. 5. Skew $T-\log p$ diagram of soundings of temperature (black line), dewpoint (blue line), and horizontal winds (wind barbs) from the RUC analyses, at (a) 0000 and (b) 0300 UTC 3 Jun 2005 at a location closest to the location of severe EDR report (Fig. 1). Horizontal winds are plotted as in Fig. 3.

\section{Results}

\section{a. Overview of the control simulation and comparison with the observations}

This section compares the large-scale features and deep convection simulated by the model in CTRL1 with observations available from the radar and satellite imagery and the RUC analysis data, in order to investigate how well the model reproduces the overall structure of the event.

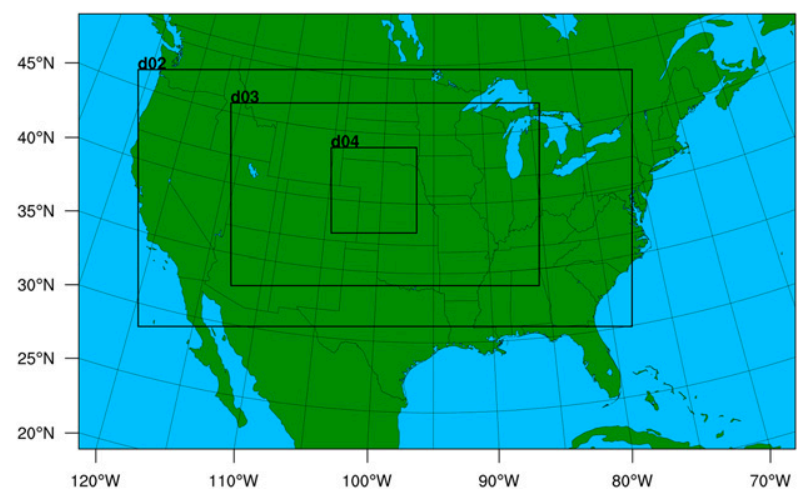

FIG. 6. Model horizontal domains D1, D2, D3, and D4, with $30-, 10-, 3.3-$, and 1.1-km horizontal grid spacing, respectively, used both for control and no latent heating simulations (discussed in the text).

Synoptic-scale flows from the 13-km RUC analysis (Figs. 7a, 8a, 9a) are first compared with those simulated in the 10-km WRF Model domain (Figs. 7b, 8b, 9b) at 0300 UTC 3 June 2005. Note that for the available RUC analysis data, 0300 UTC is closest to the observed severe EDR report (0319 UTC). A curved upper-level trough and jet stream with strong southwesterly winds $\left(>40 \mathrm{~m} \mathrm{~s}^{-1}\right)$ that extend over Wyoming and South and North Dakota are seen in Fig. 7. Figure 7b shows that the location of the jet stream is reproduced well in the WRF $10-\mathrm{km}$ domain, though the modeled jet stream is stronger over the Wyoming area than in the observations (Fig. 3b). The magnitude and direction of winds in the region of reported turbulence are similar, as is the location of the other two upper-level troughs that are seen in Fig. 7.

Surface analysis shows that the location of the low pressure system over Colorado (Fig. 8) and the distribution of surface temperature (Fig. 9), which is associated with the stationary front (see section 2), are reproduced reasonably well by the WRF Model. Also, two other simulated low pressure systems that are located over Nevada and north of Montana agree well with the RUC analysis (see also section $2 \mathrm{~b}$ ). The simulated surface winds (Fig. 8b) in the region of reported turbulence have slightly different direction and magnitude [southerly with magnitude of $15-20 \mathrm{kt}\left(1 \mathrm{kt} \approx 0.5144 \mathrm{~m} \mathrm{~s}^{-1}\right)$ ] than those in Fig. 8 a (easterly to southeasterly with magnitude $5-15 \mathrm{kt}$ ).

The overall features of the simulated MCS (Fig. 10) all agree reasonably well with the observations (Figs. 1 and 2): specifically, its overall size, the location of the most intense convective bands, stratiform precipitation relative to the surface and upper-level features, predominant north-south orientation, and southward propagation. In both the observations (Fig. 1) and simulation (Fig. 10) the northern part of the MCS has a north-south orientation. 

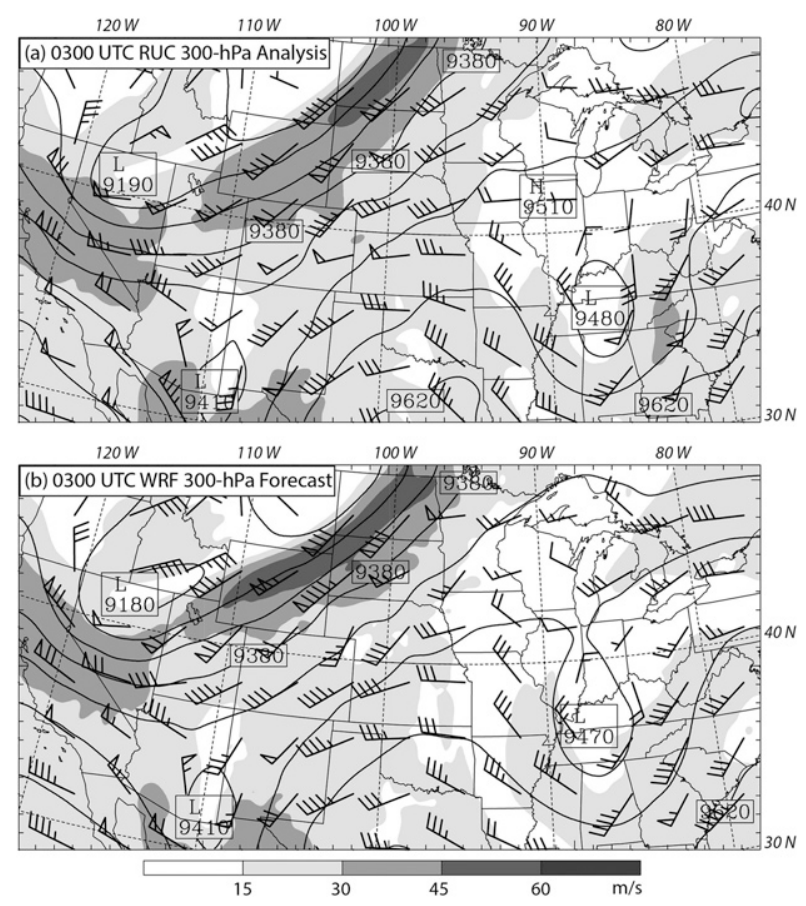

FIG. 7. Geopotential height (m, contours) superimposed on horizontal winds (shading and wind barbs) at $300 \mathrm{hPa}$ for (a) RUC and (b) WRF Model output for D2 at 0300 UTC 3 Jun 2005. Barbed symbols represent horizontal winds using the standard meteorological plotting convention (half barb $=5 \mathrm{kt}$, full barb $=10 \mathrm{kt}$, flag $=50 \mathrm{kt} ; 1 \mathrm{kt} \approx 0.5144 \mathrm{~m} \mathrm{~s}^{-1}$ ).

The southern part of the MCS comprises a more eastwest-oriented line in both the observations (Fig. 2) and simulations (Fig. 10), however the line is shorter and oriented at a slightly different angle in the simulations. The simulated MCS is slightly farther north than observed, and there is also a region of simulated active convection to the northeast of the MCS (near the Nebraska-Iowa border), which is most evident in a close up view of the simulated MCS (from D3 Figs. 11a,c), that appears more intense than observed (Fig. 1).

The differences in the simulated MCSs location and orientation may be due to the difference in low level winds and/or slightly different convective initiation and evolution, which are common errors in simulated MCSs (e.g., Duda and Gallus 2013; Squitieri and Gallus 2016). As shown earlier, the location of the EDR reports relative to the observed convective system are to the south of the convective line in the clear air, and it will be shown later that the simulated turbulence occurs in a very similar location relative to the simulated storm. Thus, the slight northward displacement and difference in orientation of the simulated MCS is not a major concern for interpretation of this case.

Even though some differences exist between the WRF simulation and the RUC analysis, it is concluded that the large-scale flow surrounding the turbulence region is captured reasonably well by the simulation. Also, given that the orientation and location of the simulated deep convection near the turbulence encounter is similar to that observed, it is sufficient for the purpose of this study to understand the key processes generating turbulence to the south of the MCS. As the MCS has position errors, the focus will be on turbulence generated in the simulations to the south of the MCS and not in the exact positions of the reports.

\section{b. Effects of moist convection on upper-level flow and turbulence generation}

Trier and Sharman (2009) showed how circulations originating from the MCS-induced upper-level outflow can provide an environment suitable for turbulence formation large distances from active convection. In the case studied here, turbulence was also reported outside and more than $50 \mathrm{~km}$ away from the regions of deep convection (see section 2). Therefore, to investigate the effect of deep convection on the upper-level flow and the environment in which the turbulence occurs, the CTRL1 simulation is compared to the NOLH1 simulation, where latent heating is disabled approximately $6 \mathrm{~h}$ before the reported turbulence at 2100 UTC (see section 3). As mentioned in section 3 , only results from the $3.3 \mathrm{~km}$ domain (D3) are analyzed here.

Comparison between CTRL1 (Figs. 11a,c) and NOLH1 (Figs. 11b,d) shows that environmental winds (i.e., without convection) are southwesterly and that superposition of convectively induced upper-level flow onto the background flow leads to divergent flow around the southwestern part of the storm and westerly winds ahead of the storm. This divergent circulation is characteristic of the upper-level outflows of warm-season MCSs (e.g., Fritsch and Maddox 1981; Trier and Sharman 2009) as well as cold season cases (Trier et al. 2012).

On the northern and northwestern side of the convective system, MCS-induced upper-level outflow contributes to the increase in wind speed. Diagnosed outflow winds are southeasterly here (not shown), while the background wind is southwesterly. Figures 11a and $11 \mathrm{c}$ also show how this northwest side of the MCS has a large area with low $\mathrm{Ri}$, which is not present in NOLH1 (Figs. 11b,d); this difference is in agreement with Trier and Sharman (2009) who showed how turbulence generation is favored on the northern side of the storm due to strong MCS-induced upper-level outflow and related increases in wind shear. This northwestern side is also the location of a number of light turbulence reports (cf. Fig. 1) and there is general agreement between the locations of the simulated low Ri in Figs. 11a and 11c and the locations of the light turbulence reports. 


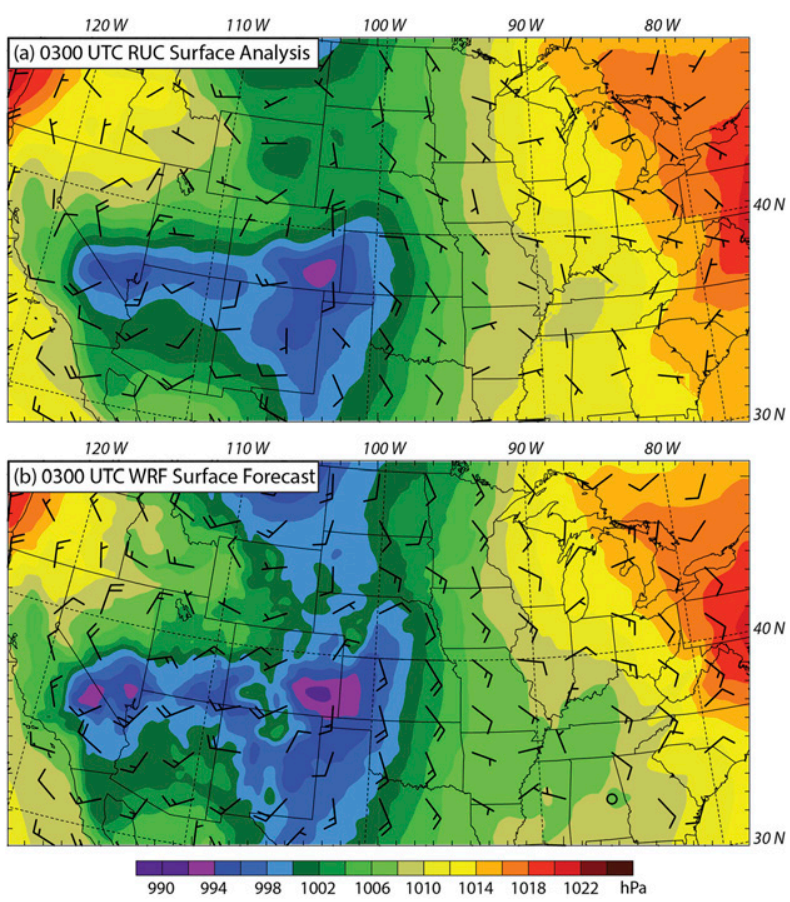

FIG. 8. Surface analysis of horizontal winds (wind barbs) and pressure (hPa, shaded) for (a) RUC and (b) WRF Model output for D2 at 0300 UTC 3 Jun 2005. Barbed symbols represent horizontal winds using the standard meteorological plotting convention (half barb $=5 \mathrm{kt}$, full barb $=10 \mathrm{kt}$, flag $=50 \mathrm{kt} ; 1 \mathrm{kt} \approx 0.5144 \mathrm{~m} \mathrm{~s}^{-1}$ ).

However, the strongest reported turbulence is located on the south side of the convective system, where the MCS-induced upper-level outflow is from the northeast, contributing to slowing and turning of winds at this level (Fig. 11a). This southern area has localized bands of low $\mathrm{Ri}$ that are very close to the location of the strongest EDR reports, but are not as widespread as on the northwest side. Further inspection demonstrates that in the NOLH1 simulation the area near the reported severe turbulence does not have low Ri or simulated TKE in this region. Thus, deep convection is apparently critical in reducing the $\mathrm{Ri}$ on the southern side of the storm, albeit in much more localized regions than to the northwest.

To further investigate the vertical structure and influence of the storm-induced upper-level outflow on the environmental flow and turbulence generation, vertical profiles of the horizontal wind components, wind shear, stability and Ri are examined in Fig. 12. These profiles are taken at a location on the south side of the convective system (red dot in Fig. 11a) for both CTRL1 and NOLH1 simulations. This location is chosen to be in the area with low Ri (specifically $\mathrm{Ri}<1$ ) for CTRL1. Additional analysis (not shown here) indicates that areas of low $\mathrm{Ri}$ move over the red dot over time, but it does not coincide with the exact location of the severe EDR report due to the slightly different orientation and location of the simulated storm.

The upper-level outflow jet is evident in Figs. 12a and $12 \mathrm{~b}$, with maximum winds at $z=12-12.5 \mathrm{~km}$. Also, the convective outflow (i.e., CTRL1-NOLH1) opposes the environmental (i.e., NOLH1) flow resulting in weaker and reversed flow in the CTRL1 simulation (cf. Fig. 11). Due to this change, vertical shear between 10 and $13.5 \mathrm{~km}$ (i.e., below and above the outflow jet) in CTRL1 is stronger than in NOLH1 (Fig. 12e). Enhanced vertical shear and reductions in static stability (Fig. 12d) contribute to decreases in $\mathrm{Ri}$ to values that are susceptible to turbulence (Fig. 12c). As Fig. 12c shows, Ri decreases to less than 1, which can support 3D turbulence (Abarbanel et al. 1984), at two layers $(\sim 11.5$ and $\sim 12.5 \mathrm{~km})$ near the flight level where the actual turbulence was observed. As demonstrated by Fig. 12, these regions of low Ri have significant spatial variability and additional analysis (shown in the next section) demonstrates temporal variability as well that coincided with the passage and evolution of the storm outflow and gravity waves. This result is in contrast with Trier and Sharman (2009) where the south side of the convective system was not supportive of turbulence due to the weaker vertical shear and greater static stability, which led to larger Ri.

This analysis shows that convectively induced upperlevel outflow and its associated vertical shear modify the environment in which turbulence occurs causing bands of low $\mathrm{Ri}$ in approximately the same location as the turbulence report. The destabilization mechanism in the current case is more complicated than in Trier and Sharman (2009), since the low Ri regions are more localized in space and time, and thereby suggests the MCS outflow is not solely responsible for the turbulence generation. The next section will show how turbulence is associated with a gravity wave that is generated by the MCS, propagates to the south, and then breaks when interacting with the environment that has been destabilized by the storm upper outflow.

\section{c. Turbulence generation mechanisms from the simulations}

The previous section analyzed the effect deep moist convection and its upper-level outflow have in creating the turbulence-prone environment on the south side of the convective system, where the storm-induced outflow opposes the background flow. It was shown that deep convection plays an important role in modifying the environment, lowering the $\mathrm{Ri}$ to values that could support turbulence. However, unlike some previous studies the low Ri to the south of the storm only occurred in localized areas, suggesting a smaller-scale process (i.e., gravity waves) was at play beyond the mesoscale 


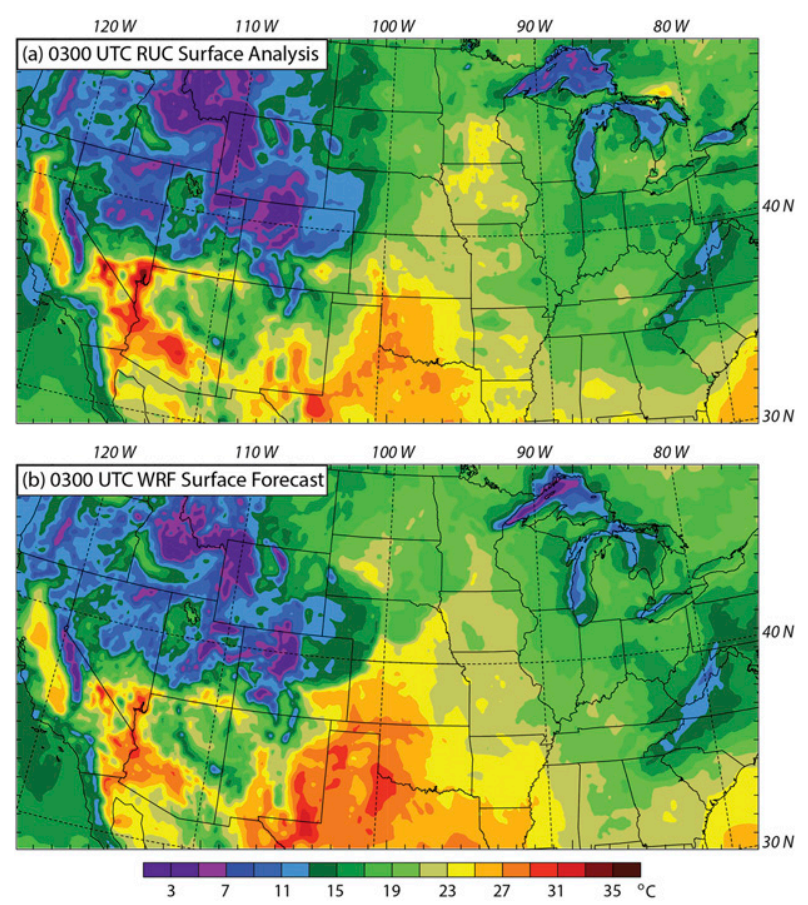

FIG. 9. As in Fig. 8, but only for temperature $\left({ }^{\circ} \mathrm{C}\right)$.

destabilization by the storm outflow. To further investigate the relationship between deep convection and NCT, model output from D4 of the CTRL1 simulation (Fig. 6), which has horizontal grid spacing of $1.1 \mathrm{~km}$, is analyzed.

It was shown in section 4a that the simulated storm has a slightly different location and orientation compared to the observations. Similarly, the simulated reduction in $\mathrm{Ri}$ is in a slightly different location (Fig. 11) and altitude (Fig. 12) compared to the turbulence report. Of course, the observed turbulence has low predictability, due to its small temporal and spatial scales and it is essentially impossible to reproduce its precise details in a deterministic simulation. Thus, it is not surprising that the simulated reductions in $\mathrm{Ri}$ are at a slightly different location and altitude compared to the observed turbulence (EDR) reports, which could simply be caused by small errors in the timing, location, and intensity of the convective system. Nonetheless, the simulated turbulence occurs a similar distance south of the simulated storm to what was actually observed, in a localized region similar to the observations. Moreover, the strongest reductions in Ri occur in two layers (viz., surrounding $z \approx 11.5$ and $z \approx 12.5 \mathrm{~km}$ ) that are within $\sim 500 \mathrm{~m}$ of the observed turbulence. Thus, the focus here will be on understanding the generation of the turbulence in these two layers to the south of the storm, rather than at the exact altitude and location of the observed event.

Figures 13 and 14 show a series of horizontal cross sections of simulated reflectivity, TKE and $\mathrm{Ri}$ at 11.5 and $12.5 \mathrm{~km}$ at different times. As mentioned above these altitudes are chosen to capture the processes leading to reduced $\mathrm{Ri}$ at these altitudes. They show areas of low $\mathrm{Ri}$ on the south side of the storm; these move farther away from the storm by 0400 UTC (Figs. 13d and $14 \mathrm{~d})$. At $12.5 \mathrm{~km}$ regions of low Ri $(0.25$ and $0.5 \mathrm{red}$ contours) coincide with smaller regions of nonzero parameterized TKE (black contours in Figs. 13 and 14) that move more than $50 \mathrm{~km}$ away from the southern cloud boundary. Although there is very little simulated
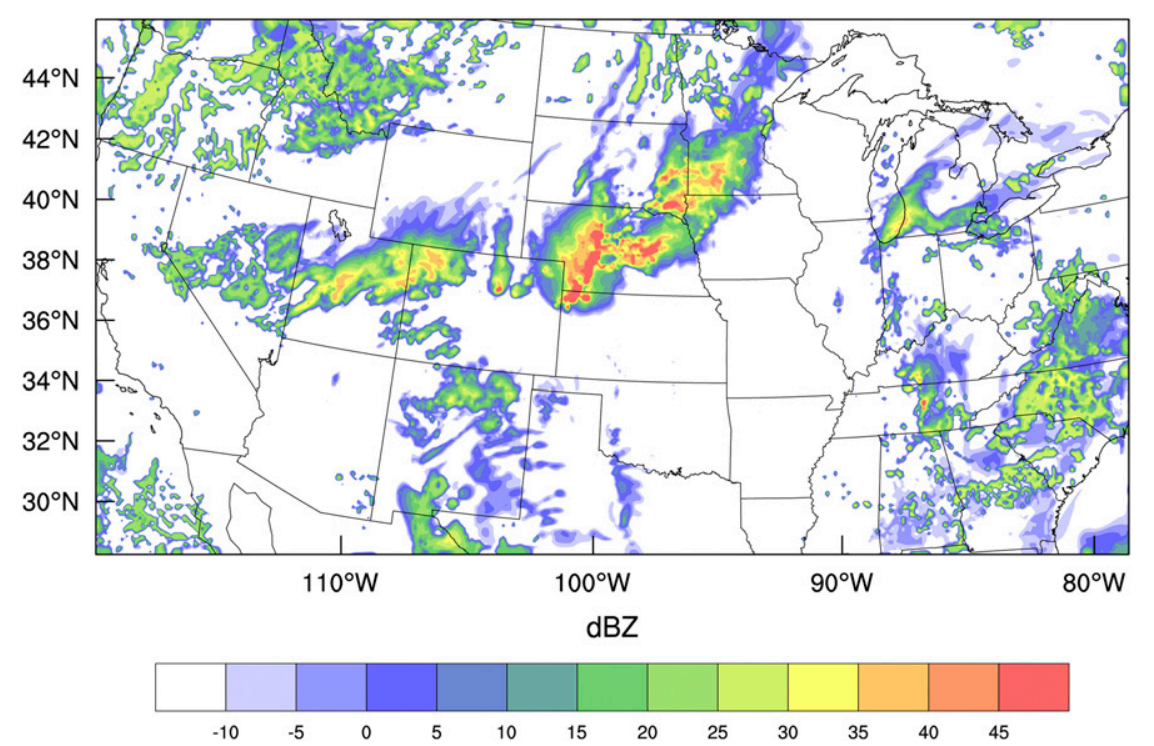

FIG. 10. Column maximum radar reflectivity simulated by the WRF Model at 0300 UTC (from D2 domain). 


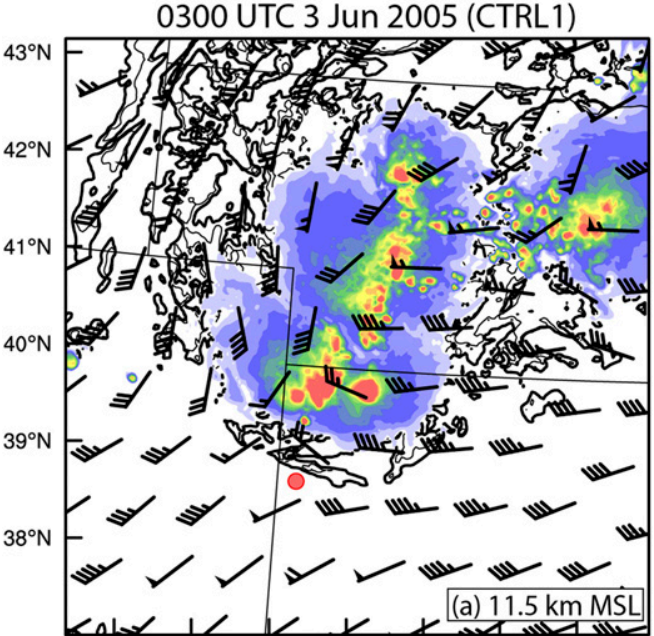

$104^{\circ} \mathrm{W} 103^{\circ} \mathrm{W} 102^{\circ} \mathrm{W} 101^{\circ} \mathrm{W} 100^{\circ} \mathrm{W} 99^{\circ} \mathrm{W} 98^{\circ} \mathrm{W}$

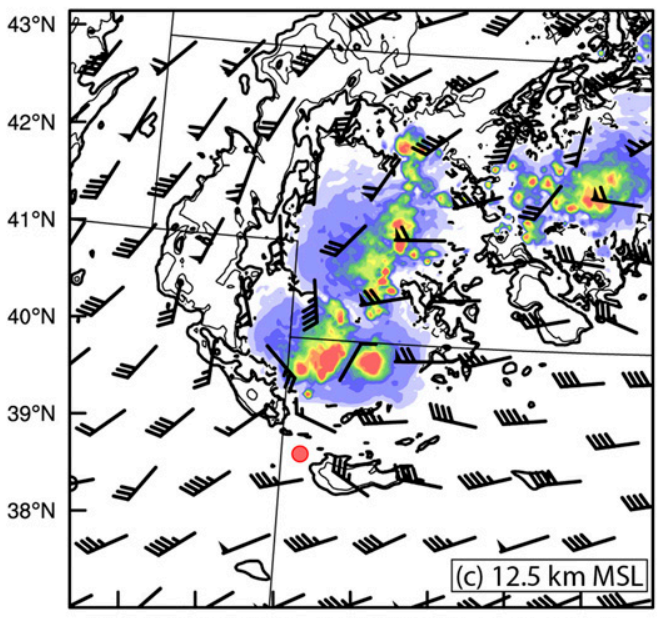

$104^{\circ} \mathrm{W} 103^{\circ} \mathrm{W} 102^{\circ} \mathrm{W} 101^{\circ} \mathrm{W} 100^{\circ} \mathrm{W} 99^{\circ} \mathrm{W} \quad 98^{\circ} \mathrm{W}$

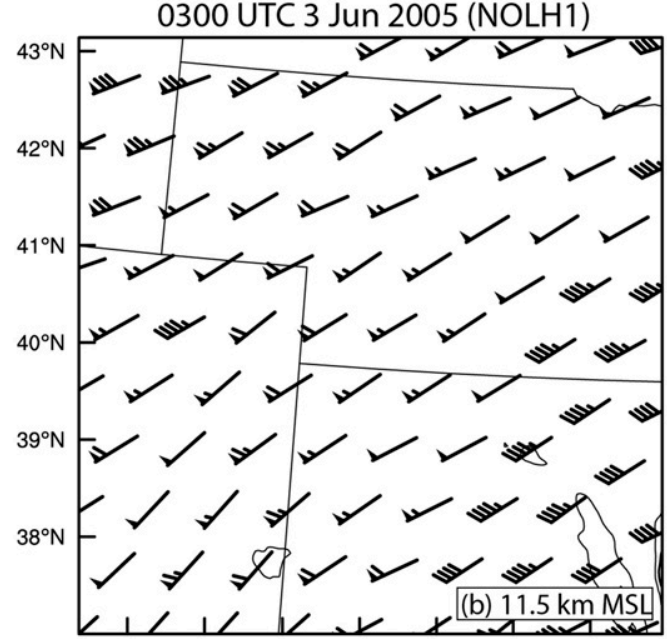

$104^{\circ} \mathrm{W} 103^{\circ} \mathrm{W} 102^{\circ} \mathrm{W} 101^{\circ} \mathrm{W} 100^{\circ} \mathrm{W} \quad 99^{\circ} \mathrm{W} \quad 98^{\circ} \mathrm{W}$

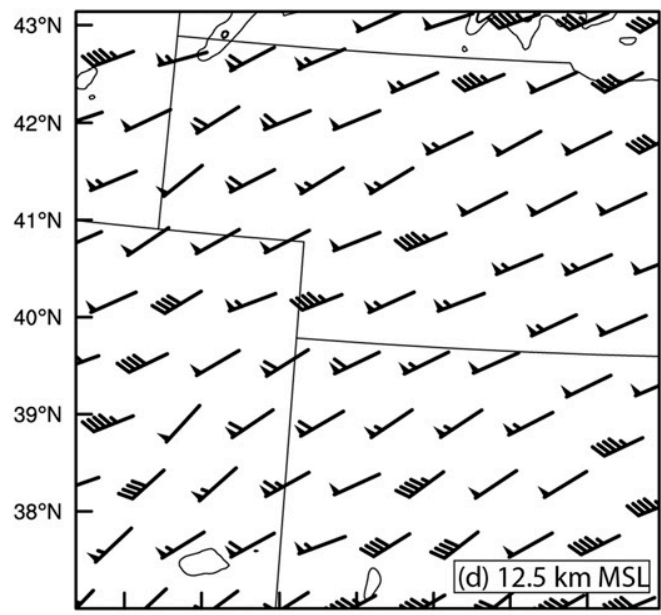

$104^{\circ} \mathrm{W} 103^{\circ} \mathrm{W} 102^{\circ} \mathrm{W} 101^{\circ} \mathrm{W} 100^{\circ} \mathrm{W} 99^{\circ} \mathrm{W} \quad 98^{\circ} \mathrm{W}$

$\mathrm{dBZ}$

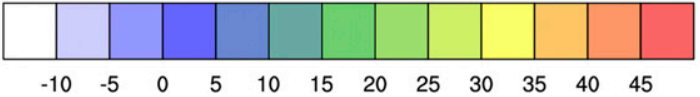

FIG. 11. Horizontal winds (wind barbs), simulated radar reflectivity (dBZ), and Ri (black contours, bold contour is $\mathrm{Ri}=1$ and thin contour is $\mathrm{Ri}=0.5$ ) at (a) $11.5 \mathrm{~km}$ and (c) $12.5 \mathrm{~km}$ MSL for the control (CTRL1) simulation at 0300 UTC 3 Jun 2005. (b),(d) Horizontal winds and Ri at 11.5 and $12.5 \mathrm{~km}$ MSL for the no latent heating (NOLH1) simulation, respectively. The red dot in (a),(c) denotes the location of the vertical profile that is shown in Fig. 12. Barbed symbols represent horizontal winds using the standard meteorological plotting convention (half barb $=5 \mathrm{kt}$, full barb $=10 \mathrm{kt}$, flag $=50 \mathrm{kt} ; 1 \mathrm{kt} \approx 0.5144 \mathrm{~m} \mathrm{~s}^{-1}$ ).

TKE at these heights, regions of low Ri indicate that the area should be more susceptible to turbulence. After 0400 UTC regions with reduced Ri become more widespread and move more than $100 \mathrm{~km}$ away and to the southeast from the storm (not shown). As mentioned earlier, there are widespread areas of low $\mathrm{Ri}$ and simulated TKE in other locations around the storm, especially on the northwest side of the storm where there are many light turbulent reports (Fig. 1) and the
MCS-induced outflow is stronger (see section $4 \mathrm{~b}$ ) but these areas are not discussed further as the focus is on the stronger reports to the south.

Analysis of the vertical velocity in Fig. 15 reveals extensive gravity waves radiating from the convective system. In the region of localized reduced $\mathrm{Ri}$ and nonzero TKE to the south of the storm (i.e., close to the observed turbulence encounter) there is a packet of waves with east-west-oriented wave fronts propagating 

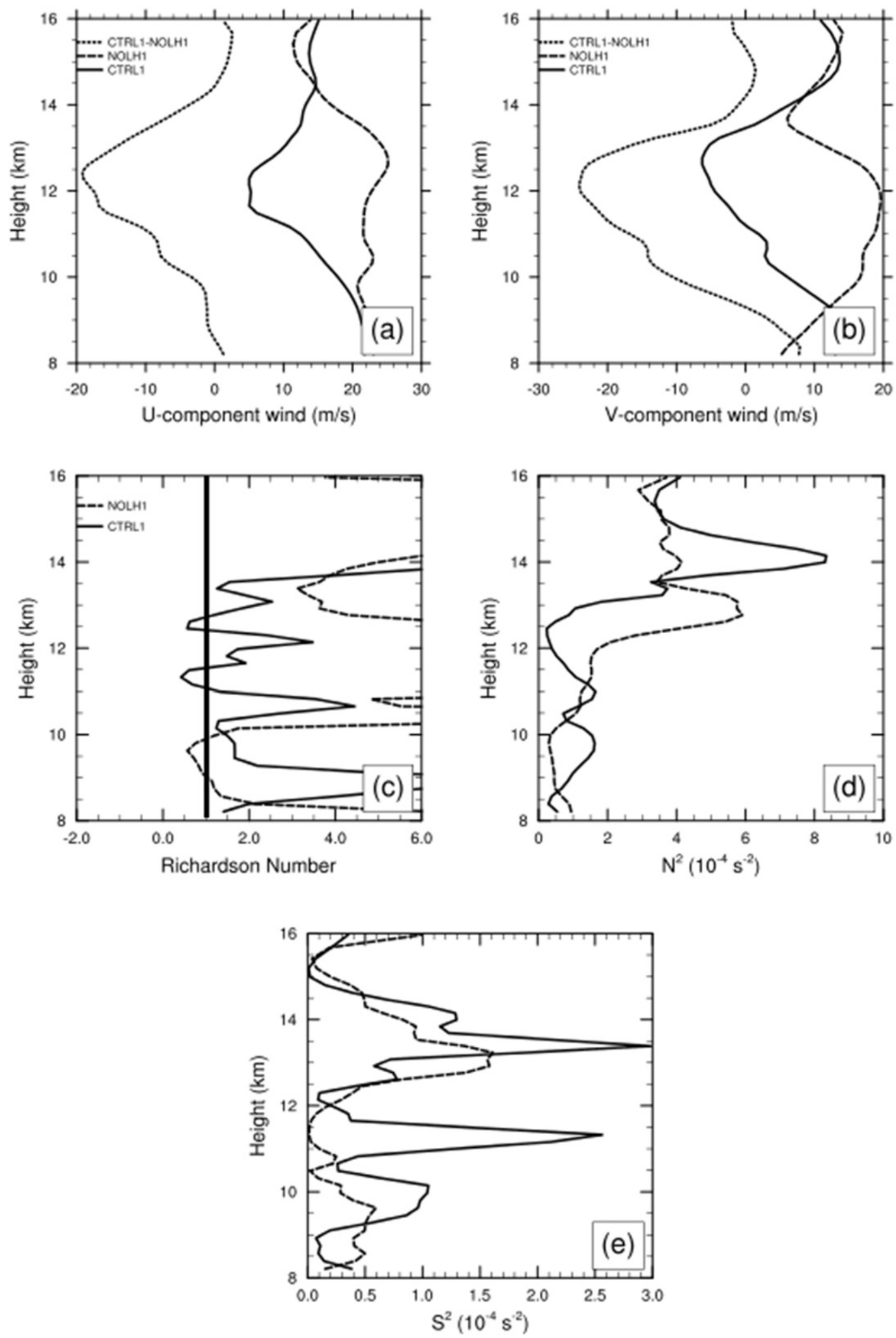

FIG. 12. Vertical profiles of (a) zonal and (b) meridional wind components, (c) Ri, and its contributions from (d) the squared Brunt-Väisälä frequency $\left(N^{2}\right)$ and (e) the squared vertical shear $\left(S^{2}\right)$ at a location shown by the red dot in Fig. 11a. Solid line is CTRL1, dashed is NOLH1, and dotted line is CTRL1-NOLH1. 
D04 of CTRL1 at $z=11.5 \mathrm{~km} \mathrm{MSL}$
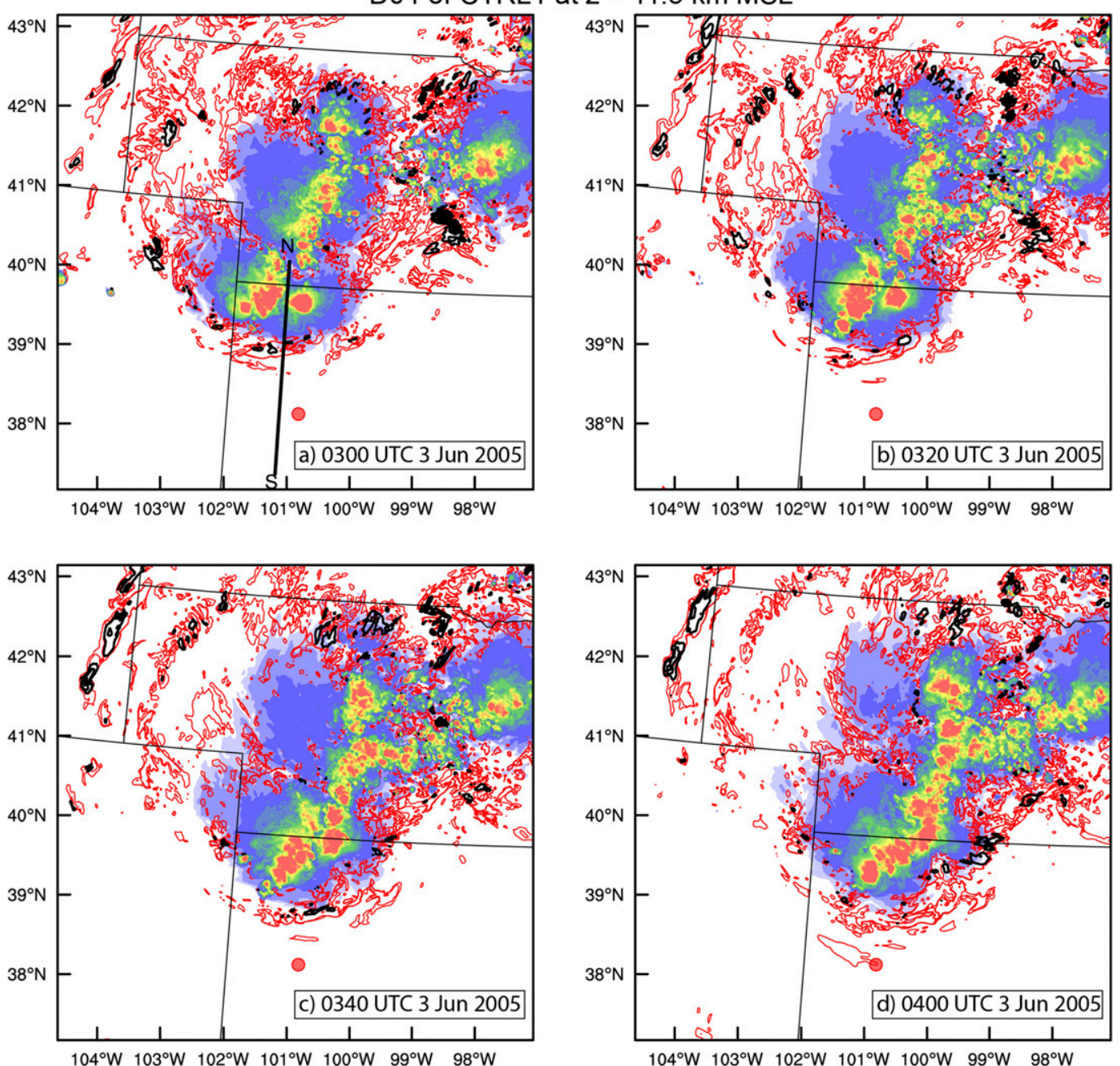

$\mathrm{dBZ}$

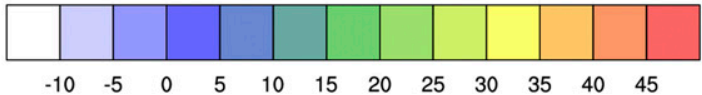

FIG. 13. Horizontal cross section of simulated radar reflectivity (dBZ), TKE $\left(\mathrm{m}^{2} \mathrm{~s}^{-2}\right.$, black contours), and Ri (red contours) through $z=11.5 \mathrm{~km}$ at (a) 0300, (b) 0320, (c) 0340, and (d) 0400 UTC 3 Jun 2005 from D04 of CTRL1 simulation. TKE is contoured with a $0.5 \mathrm{~m}^{2} \mathrm{~s}^{-2}$ contour interval, starting at $0.5 \mathrm{~m}^{2} \mathrm{~s}^{-2}$, while Ri is contoured by 0.25 and 0.5 contour intervals. The black line $\mathrm{SN}$ in (a) denotes the location of the vertical cross section displayed in Figs. 16 and 17. The red dot denotes the location of the severe EDR report (cf. Fig. 1).

toward the south. These waves are highlighted by the box in Fig. 15b; within this box there are a number of coherent wave fronts, along with a broader area of upward motion immediately to the south of the wave fronts. It is this broader region of upward motion that corresponds directly to the area of reduced $\mathrm{Ri}$ seen in Fig. 14b.

To further understand the relationship between convection, gravity waves and turbulence, vertical cross sections through the southward-propagating waves and low Ri regions are analyzed (Figs. 16 and 17). This cross section is along the $\mathrm{SN}$-oriented transect marked in Fig. 13a, passing through the wave region highlighted in Fig. 15b. Figures $16 \mathrm{a}$ and $16 \mathrm{c}$ show that by 0300 UTC the storm is well developed and updrafts are penetrating the tropopause and reaching a height of about $15 \mathrm{~km}$ by 0320 UTC (Figs. 16b,d). As the updraft overshoots into the lower stratosphere gravity waves are generated directly above clouds; this is evident in the wavelike perturbations in vertical displacement of the potential 
D04 of CTRL1 at $z=12.5 \mathrm{~km} \mathrm{MSL}$
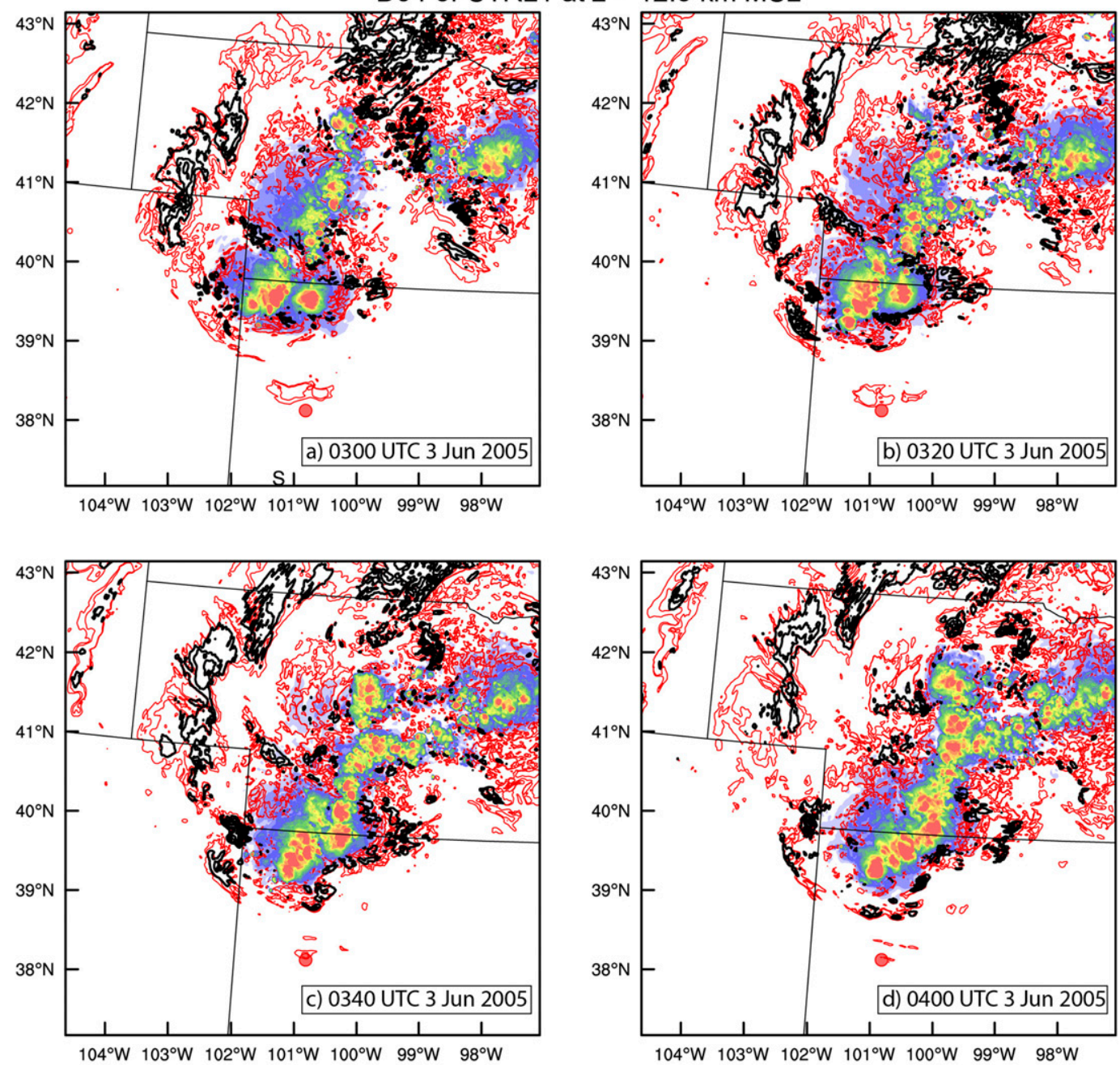

$d B Z$

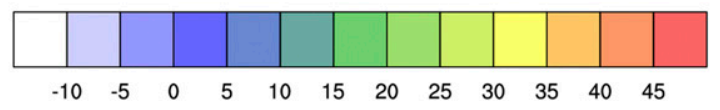

FIG. 14. As in Fig. 13, but at $z=12.5 \mathrm{~km}$.

temperature field, horizontal velocity, and vertical velocity (Figs. 16 and 17; $200<x<300 \mathrm{~km}$ and $z>13 \mathrm{~km}$ ). The generation mechanisms of gravity waves directly above convection are well established, having been discussed in detail by many previous studies (e.g., Fovell et al. 1992; Lane et al. 2003; Song et al. 2003).

Figure 16 also shows large-amplitude wavelike perturbations in the potential temperature to the south of the storm, coinciding with $\mathrm{Ri}<1$ (bold contours in Figs. 16a,b). This large-amplitude gravity wave is propagating southward away from the storm (cf. Fig. 15). The isentropes are steepening and overturning (Figs. 16a,b; $100<x<130,11<z<13 \mathrm{~km}$ ), which identifies wave breaking and instability. These figures also show that the regions of gravity wave steepening and overturning coincide with areas with reduced $\mathrm{Ri}$, with the layer between 11.5 and $12.5 \mathrm{~km}$ having Ri less than or equal to 0.25 (dark bold line in Figs. 16a,b). Figures 16c and 16d show that wind in the wave region is negative, with enhanced shear above and below (see also Fig. 18 and discussion below). Regions of wave steepening and overturning are also coincident with the relatively narrow region of simulated TKE (shaded contours in Figs. 16a,b), suggesting that this wave breakdown causes the parameterized turbulence and associated $\mathrm{Ri}<0.25$. Moreover, the vertical velocity (Fig. 17a) shows a largeamplitude coherent wave packet with about a $20 \mathrm{~km}$ wavelength immediately to the north of the breaking 

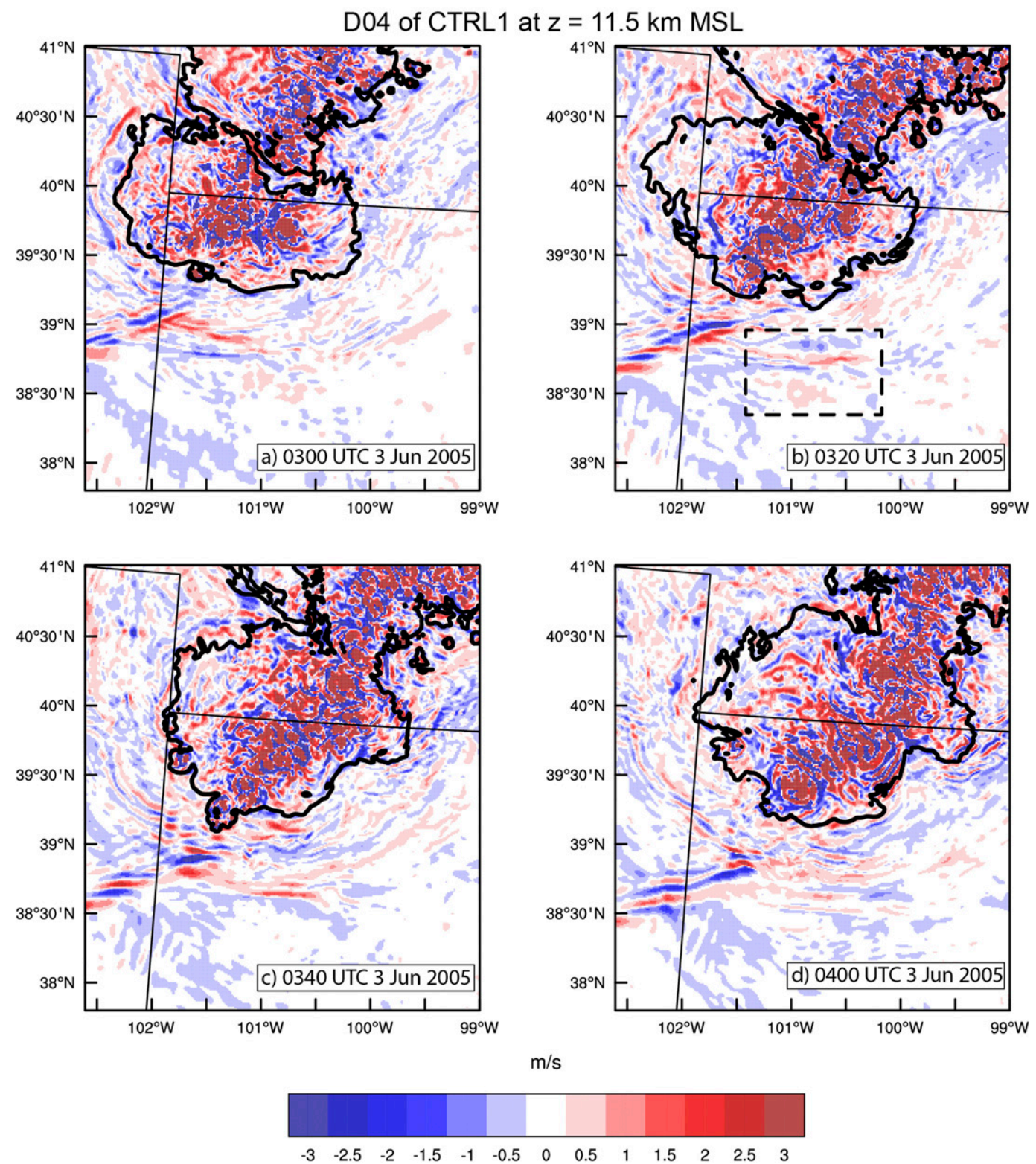

FIG. 15. As in Fig. 13, but for vertical velocity $\left(\mathrm{m} \mathrm{s}^{-1}\right)$ and over a smaller area. The black contour represents zero reflectivity outline $(0 \mathrm{~dB} Z)$, the black dashed box in (b) highlights a region discussed in the text.

region-this is the wave packet identified in Fig. $15 \mathrm{~b}$. In the breaking region the vertical velocity has longer horizontal scale, consistent with the broader region of upward motion in Fig. 15b. Later in the simulation, as the wave is propagating farther to the south and continues to break, the area with TKE becomes more widespread and elongated (not shown).

To further understand the relationship between the large-amplitude gravity wave and reductions in $\mathrm{Ri}$ to values that support turbulence, vertical profiles of $\mathrm{Ri}$, wind shear, static stability and wind speed are presented in Fig. 18, at locations outside (solid vertical line in
Fig. 16a) and inside the gravity wave region (dashed vertical line in Fig. 16a).

The vertical profile of Ri outside the gravity wave area (solid line in Fig. 18a) shows that Ri is positive and larger than 1 everywhere. Yet, it is reduced considerably in shallow layers surrounding $z \approx 10.5$ and $z \approx 12 \mathrm{~km}-$ layers similar to those examined earlier. Inside the gravity wave area (dashed line in Fig. 18a) Ri is decreasing with height throughout the upper troposphere/lower stratosphere $(z>10 \mathrm{~km})$ and is also negative at $z \approx 12.5 \mathrm{~km}$. At altitudes where $\mathrm{Ri}$ is decreasing and becoming negative, the stability sharply varies with height and goes to zero 

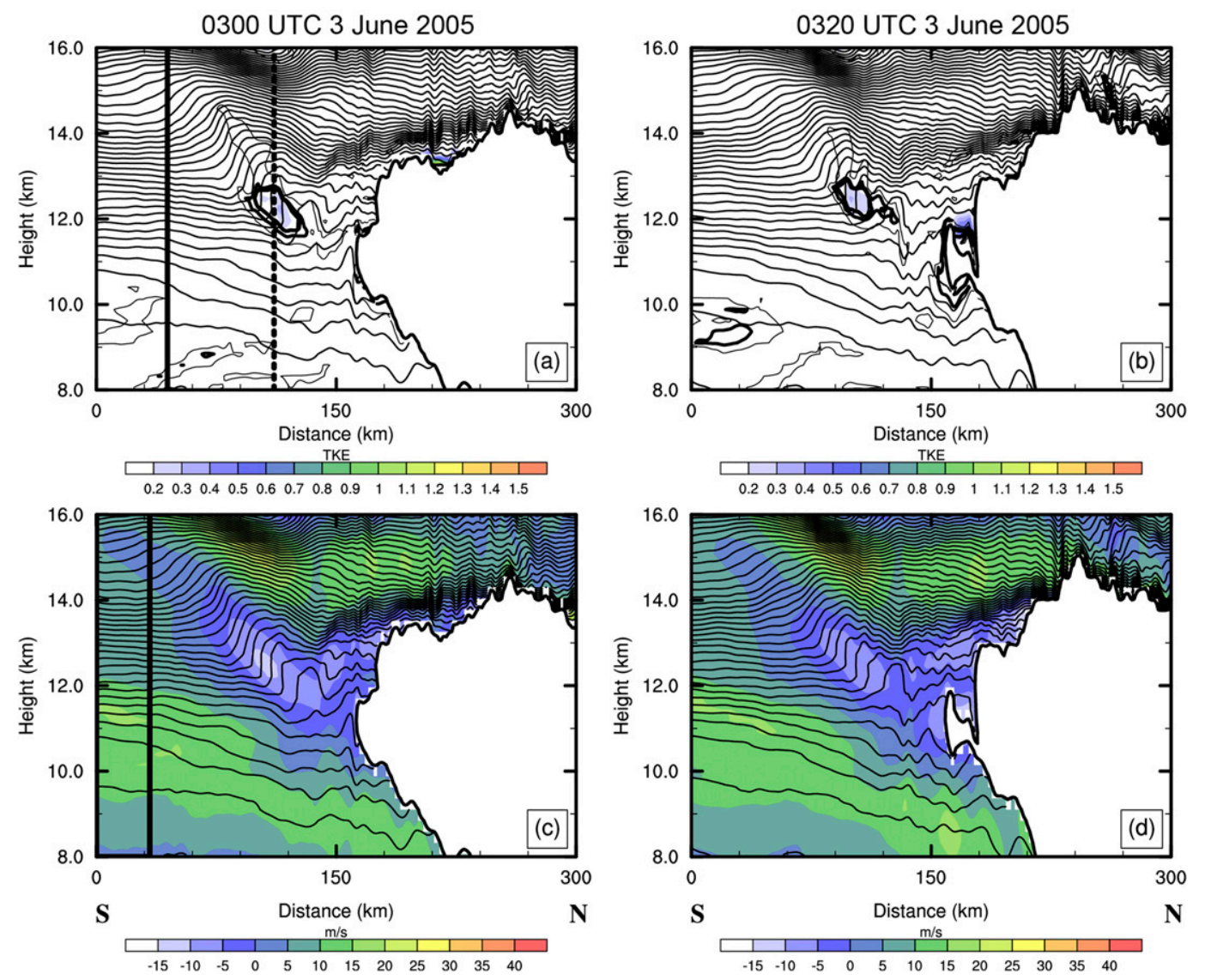

FIG. 16. Vertical cross section of (a),(b) potential temperature (black contours with $2 \mathrm{~K}$ intervals), TKE $\left(\mathrm{m}^{2} \mathrm{~s}^{-2}\right.$, shaded), and $\mathrm{Ri}$ (black contours, bold contour is $\mathrm{Ri}=0.25$ and thin contour is $\mathrm{Ri}=1$ ); (c), (d) meridional wind $\left(\mathrm{m} \mathrm{s}^{-1}\right.$ ) taken along line SN in Fig. 13a, at (left) 0300 and (right) 0320 UTC 3 Jun 2005. Also shown is the $0.05 \mathrm{~g} \mathrm{~kg}^{-1}$ cloud outline (thick solid line). Solid and dashed vertical lines in (a) denote vertical profiles that are shown in Fig. 18. The black rectangle in (c) denotes the area over which the wind and potential temperature are averaged for the Scorer parameter calculation in Fig. 20.

at $\approx 12.5 \mathrm{~km}$ (Fig. 18b, dashed line). Figure $18 \mathrm{c} \mathrm{dem}-$ onstrates that the wind shear is a local maximum at this level, both within the gravity wave region and outside it, coinciding with the storm upper-outflow jet. The negative stability and $\mathrm{Ri}$ at this level identifies the breaking/overturning of the gravity wave. This analysis further shows that the storm upper outflow has destabilized the environment by lowering the $\mathrm{Ri}$, making it more favorable for turbulence, but not reducing $\mathrm{Ri}$ sufficiently to induce turbulence. It is the additional influence of the gravity wave breaking that creates the localized regions of low Ri that can support turbulence. This result is in some ways similar to a case observed on 5 August 2005 and described by Fovell et al. (2007) and Lane et al. (2012); for this case a horizontally propagating gravity wave was able to propagate ahead of an MCS and reduce the already low Ri to values supportive of turbulence. Moreover, the wave on 5 August 2005 was effectively ducted, which allowed it to travel significant horizontal distances.

Since the turbulence is associated with the overturning wave to the south of the convection, it is instructive to examine its temporal and spatial characteristics. For this, a Hovmöller diagram at $z=11.5 \mathrm{~km}$ is shown in Fig. 19, for a portion of the same cross section as in Fig. 16. The evolution of vertical velocity shows wave structures that propagate in the southward direction relative to the ground, all with similar phase speed. The region of the simulated wave breaking and turbulence at approximately 0300 UTC and $100<x<130 \mathrm{~km}$ features a broad region of upward motion (which was discussed earlier and identified in Figs. 15b and 17). Immediately to the north of this region is the (unbroken) large-amplitude wave packet, that contain coherent wave fronts (with a positive phase marked with a yellow line on Fig. 19). Later (after 0400 UTC) there are additional waves that have more coherence and slightly 
(a) 0300 UTC 3 June 2005

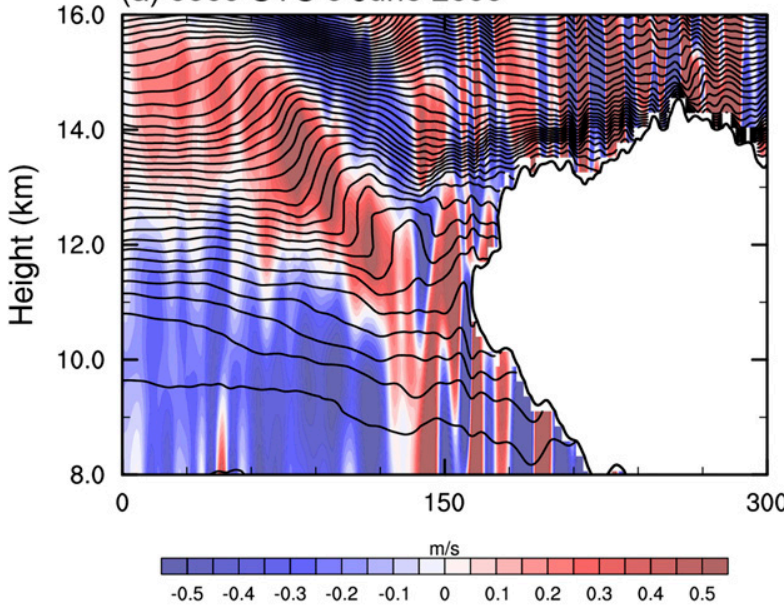

(b) 0320 UTC 3 June 2005

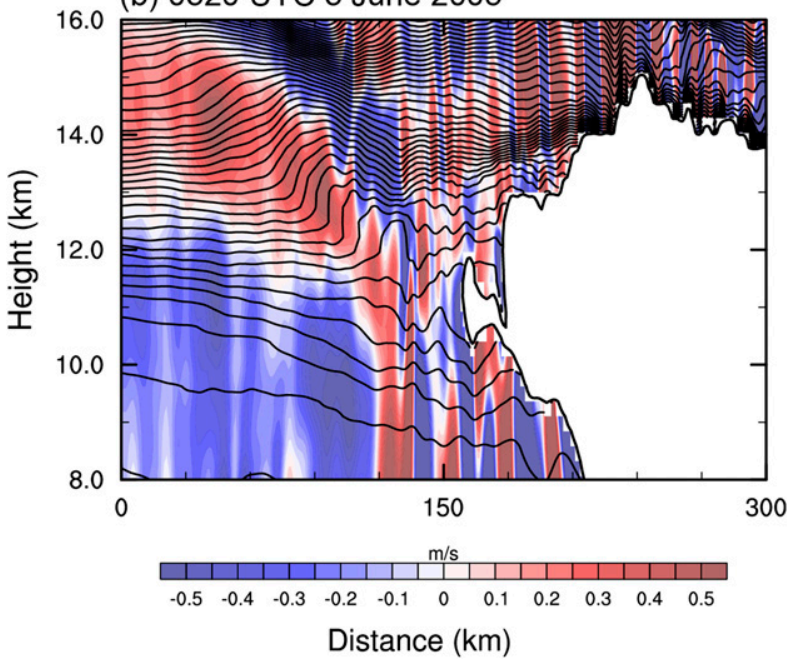

FIG. 17. As in Fig. 16, but for vertical velocity $\left(\mathrm{m} \mathrm{s}^{-1}\right)$ : (a) 0300 and (b) 0320 UTC 3 Jun 2005.

shorter horizontal wavelengths. For the wave packet immediately to the north of the breaking region it is calculated from Fig. 19 to have a period of $40 \mathrm{~min}$ and horizontal wavelength $\lambda$ of approximately $21 \mathrm{~km}$; which gives a phase speed of $c=-9 \mathrm{~m} \mathrm{~s}^{-1}$.

As discussed above, between $z \approx 11.5$ and $z \approx 12.5 \mathrm{~km}$ there is wave steepening and overturning, which is identified through inspection of the isentropes in Figs. 16 and 17 . Within this overturning there is a region where the wave-relative winds reverse, that is, become less than $-9 \mathrm{~m} \mathrm{~s}^{-1}$ (see Figs. 16c, 16d, and 18e) which is known as a wave-induced critical level (e.g., Peltier and Clark 1979; Clark and Peltier 1984). (Note that a critical level is defined as a level where wave phase speed is equal to the wind speed). Specifically, comparison of the above calculated wave phase speed $\left(c=-9 \mathrm{~m} \mathrm{~s}^{-1}\right)$ with the meridional wind profile inside the gravity wave area (Fig. 18e, dashed line) shows that $v-c=0$ at $z \approx 12.5 \mathrm{~km}$. This nonlinear breaking process occurs when the wave amplifies sufficiently such that a critical level is induced locally within the wave. For this case the wave amplification and breaking occurs over a shallow layer only about a kilometer deep, the discussion below seeks to understand the localization of this amplification that leads to nonlinear breaking.

Inspection of the vertical velocity in Fig. 17 shows that this wave is tilted from the vertical above approximately $12.5 \mathrm{~km}$, while below this height its phase lines are approximately vertical, indicating that the wave may be evanescent or trapped below $12.5 \mathrm{~km}$. Gravity waves that are seen below $10.5 \mathrm{~km}$ in Fig. 17 and to the south of the cloud boundary have shorter horizontal wavelength and vertically oriented phase lines, which also indicates they are trapped or evanescent gravity waves. Above about $13 \mathrm{~km}$, the waves have distinctly longer wavelengths than below, suggesting that the shorter wavelength waves are filtered somewhere below. Vertically oriented phase lines that are seen directly above the cloud are associated with gravity waves generated coincident with overshooting updrafts (cf. Fig. 16 and discussion above).

To further explain the characteristics of gravity wave propagation at 0300 UTC the vertical structure of the Scorer parameter analyzed in Fig. 20. The Scorer parameter $\left(l^{2}\right)$ is calculated using

$$
l^{2}=\frac{N^{2}}{(U-c)^{2}}-\frac{\frac{d^{2} U}{d z^{2}}}{(U-c)}+\frac{1}{H_{s}} \frac{\frac{d U}{d z}}{(U-c)}-\frac{1}{4 H_{s}^{2}},
$$

where $N$ is the Brunt-Väisälä frequency, $U$ is the horizontal wind component in the direction of the cross section (Fig. 20b), $H_{s}$ is the density-scale height, and $c$ is phase speed (Nappo 2002). The wind and $N^{2}$ used to calculate $l^{2}$ are horizontally averaged over the region that is marked by the black vertical lines in Fig. 16c, and phase speed calculated from Fig. 19 is used (i.e., $c=-9 \mathrm{~m} \mathrm{~s}^{-1}$ ). This profile is taken ahead of the wave region and the spatial averaging is conducted to minimize any influence of gravity waves on the profile. Although there may be some waves still influencing the profile, taking the profile farther away from the storm would not be representative of the near-storm environment that is the primary interest. Also shown in Fig. 20a is a vertical line depicting $k^{2}=(2 \pi / \lambda)^{2}$, where $\lambda=21 \mathrm{~km}$ is the horizontal wavelength determined from Fig. 19 for waves at $z=11.5 \mathrm{~km}$.

The vertical profile of the Scorer parameter in Fig. 20a shows that $l^{2}$ is less than $k^{2}$ (and negative) over two 

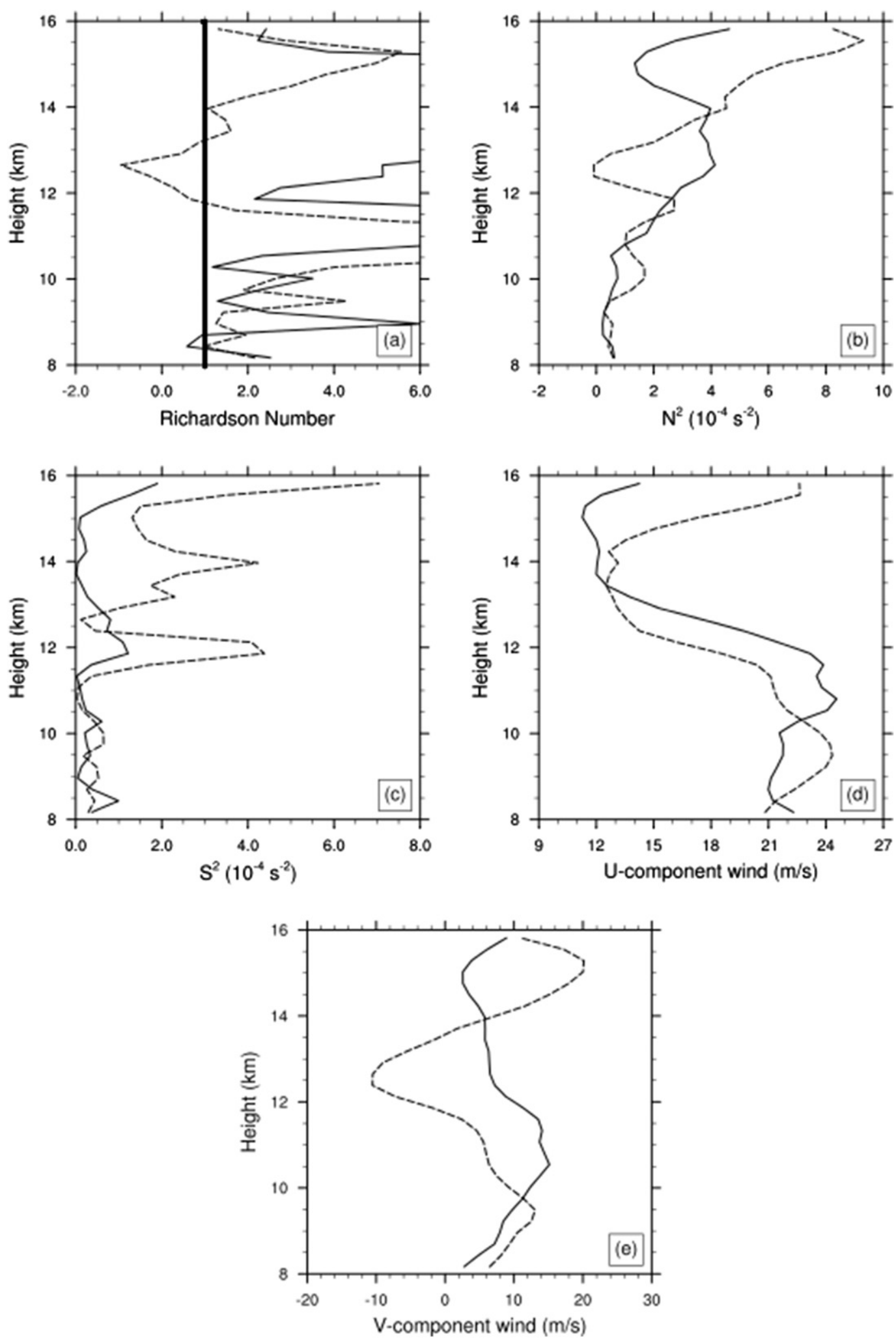

FIG. 18. Vertical profiles of (a) Ri and its contributions from (b) the squared Brunt-Väisälä frequency $\left(N^{2}\right)$ and (c) the squared vertical shear $\left(S^{2}\right)$ taken along the vertical lines shown in Fig. 16a. The profiles of zonal and meridional wind components are shown in (d),(e), respectively. The solid line denotes area outside the gravity wave, while the dashed line denotes area inside the gravity wave. 


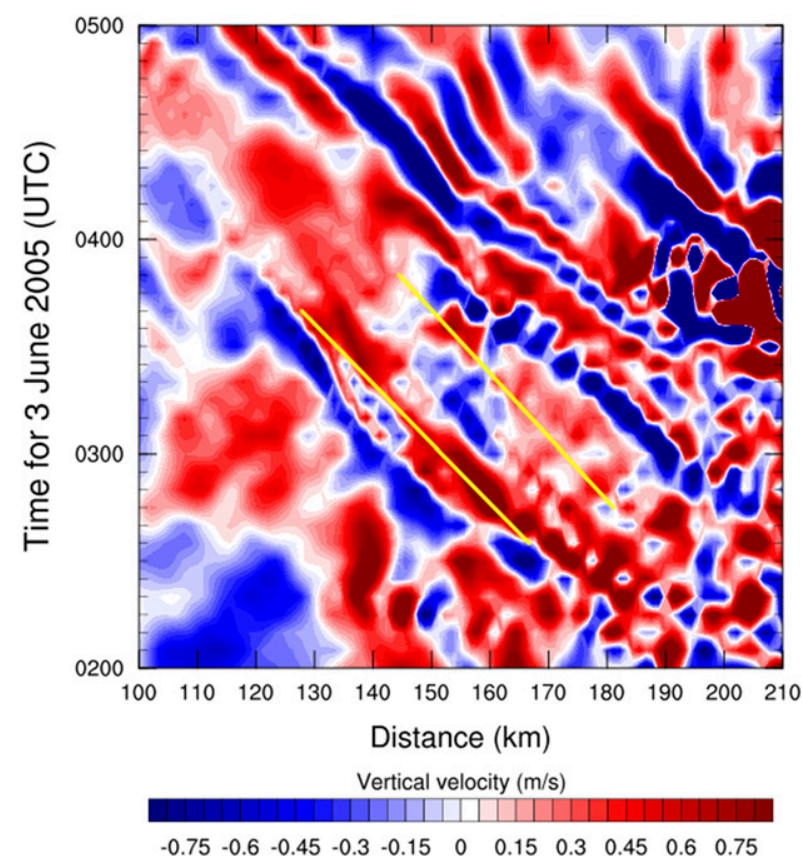

FIG. 19. Hovmöller diagram of vertical velocity at $z=11.5 \mathrm{~km}$ for the cross section along the SN line in Fig. 13a. Also shown are lines (yellow) that highlight the wave structure propagating at $c=-9 \mathrm{~m} \mathrm{~s}^{-1}$. See text for discussion.

shallow layers (centered at $z \approx 10.75$ and $z \approx 12.5 \mathrm{~km}$ ) surrounding the breaking region; the gravity wave packet would be evanescent in these two layers. The upper layer occurs in negative meridional shear (Fig. 20b). The large-amplitude gravity wave amplifies and breaks in this negative shear zone, which is also between the two layers of negative $l^{2}-k^{2}$. It is possible that these two evanescent layers cause partial wave reflection (e.g., Klemp and Lilly 1975; Nappo 2002) and form a leaky wave duct that contributes to the wave amplification. (This duct is leaky as waves are evident above and below the evanescent layers). The existence of the duct is relatively insensitive to the choice of phase speed, as shown by the additional curves on Fig. 20a for $c=-9 \pm 3 \mathrm{~m} \mathrm{~s}^{-1}$. Yet, because of the complicated three-dimensional evolving nature of the near-cloud environment there is some uncertainty in the application of the Scorer parameter analysis to this case. Moreover, further analysis demonstrates that the Wentzel-Kramers-Brillouin (WKB) approximation (i.e., the underlying theory used to derive the Scorer parameter) is violated over a few shallow layers due to the large vertical shears causing the vertical wavenumber to vary rapidly (not shown). Nonetheless, the Scorer parameter profile is still useful in explaining aspects of the wave propagation and the governing processes in the simulations.
Thus, the above analysis suggests that wave amplification, potentially caused by partial wave ducting/reflection, leads to wave breaking and turbulence in a shallow layer about $50 \mathrm{~km}$ to the south of the storm. The wave breaking occurs via a nonlinear process that is similar in concept to that described by Peltier and Clark (1979, 1983) for mountain waves. The turbulence generation occurs in an environment that is already destabilized by the upper-level storm outflow-the nonlinear gravity wave provides an additional perturbation that locally destabilizes the flow to produce localized regions of turbulence.

\section{Summary and discussion}

This study has examined a case of moderate-to-severe turbulence encounters associated with a squall line that developed near a stationary front on 3 June 2005. The majority of turbulence reports were located on the south side of the squall line and large distances from the active convective regions.

A convection-permitting configuration of the WRF Model was used to investigate the impact of deep moist convection on out-of-cloud turbulence. Turbulence was parameterized since the smallest horizontal grid spacing used in the model is $1.1 \mathrm{~km}$, which does not resolve turbulence. The main synoptic features including the surface stationary front and the jet stream are well simulated in a control run, even though the simulated deep convection was located more to the north compared to the observed one. Due to this difference, the simulated turbulence and regions with lowest Ri do not exactly coincide with the observed EDR reports, though they are still located on the south side of the system in a very similar location relative to the observed deep convection. An additional simulation was conducted where latent heating was disabled in order to elucidate the influence of the convectively induced upper-level outflow on the background southwesterly jet.

Comparison of the control run with the simulation with no latent heating showed that the influence of the anticyclonic outflow emanating from the prefrontal squall line is such that it opposes and reduces environmental flow on the south side of the storm, while it enhances the background flow on the north and northwest side of the storm. This is in agreement with the previous studies that investigated storm-induced upperlevel outflows (e.g., Fritsch and Maddox 1981; Trier and Sharman 2009). Additionally, at $13 \mathrm{~km}$ flow is enhanced due to the storm-induced outflow and this increases vertical shear near the flight levels (11-12 km), in contrast to the simulation with no latent heating. Also, the Richardson number (Ri) is low and less 

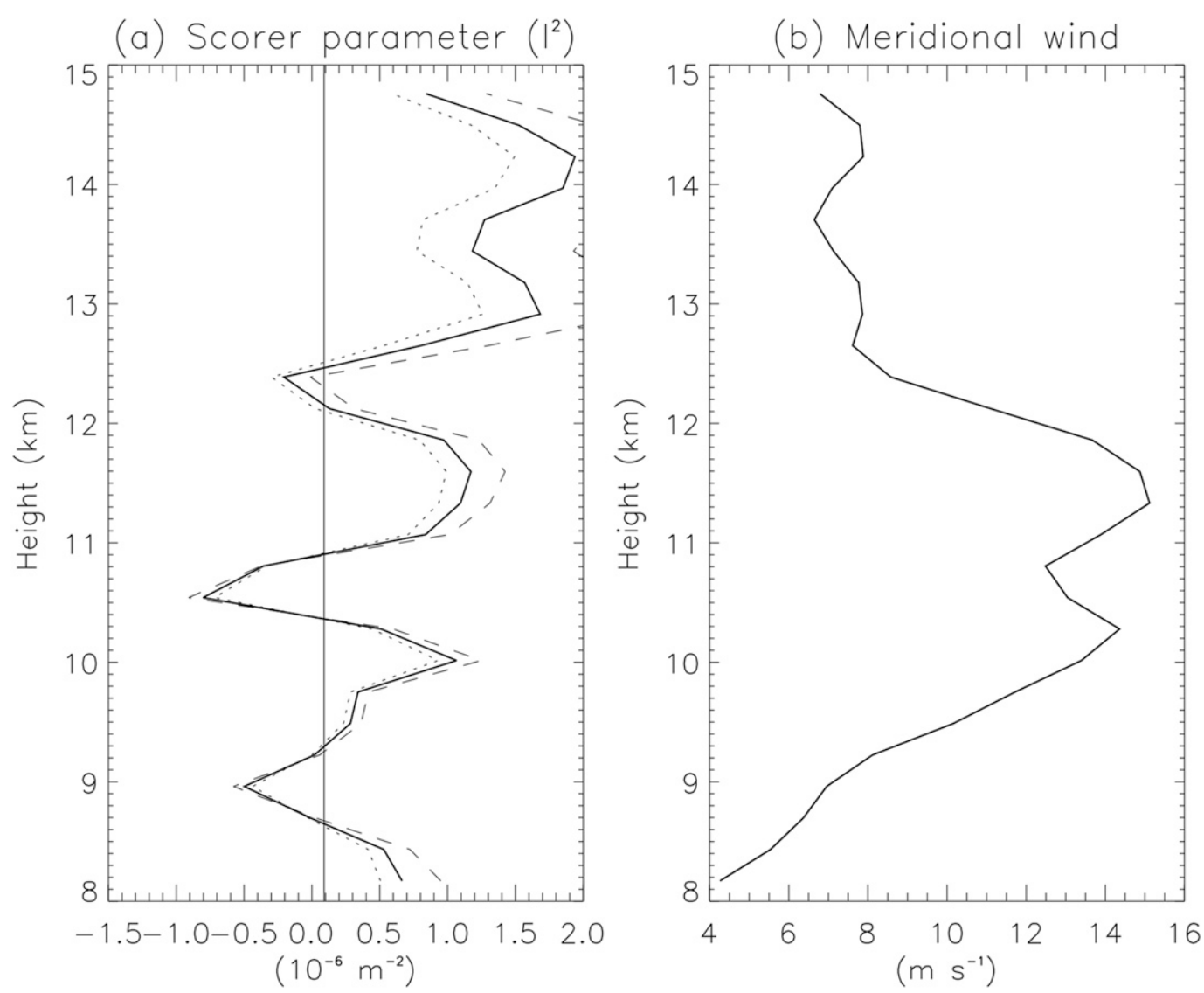

FIG. 20. Vertical profile of the Scorer parameter $\left(l^{2}\right)$ and averaged along-section (meridional) wind at 0300 UTC 3 Jun 2005. Here the wind is averaged over the distance indicated by the black rectangle in Fig. 16c. In (a) the vertical line is $k^{2}=(2 \pi / \lambda)^{2}$, where $\lambda=21 \mathrm{~km}$, the thick solid line is for $c=-9 \mathrm{~m} \mathrm{~s}^{-1}$, the dotted line is for $c=-12 \mathrm{~m} \mathrm{~s}^{-1}$, and the dashed line is for $c=-6 \mathrm{~m} \mathrm{~s}^{-1}$.

than 1 in a broad region in the control run compared to the simulation without latent heating, suggesting that moist convection is playing an important role in turbulence generation by destabilizing the environment over a mesoscale region, within which the turbulence occurs.

Results from the high-resolution domain that has horizontal grid spacing of $\Delta x=1.1 \mathrm{~km}$ are used to deduce possible mechanisms associated with moist convection that are responsible for the observed severe turbulence. These results show that turbulence that is observed in the clear air and on the south side of the storm is associated with a large-amplitude gravity wave that is generated by moist convection and propagates away from the storm. This simulation produced regions of $\mathrm{Ri}$ lower than 1, which extended large distances from active convection. More localized regions with simulated $\mathrm{TKE}$ and $\mathrm{Ri} \leq 0.25$ were also produced and associated with the gravity waves.

The large-amplitude gravity wave propagated away from the storm and broke in the region with enhanced vertical shear associated with storm-induced upper-level outflow. During the wave overturning, the static stability was reduced and vertical shear increased, both causing localized reductions in $\mathrm{Ri}$ to values that produced parameterized turbulence. Analysis of the Scorer parameter showed two evanescent layers surrounding the breaking region, which may have created a partial wave duct leading to the wave amplification that created a wave-induced critical level.

Consistent with the observations, the simulated wave breaking and turbulence generation occurred about $50 \mathrm{~km}$ to the south of the simulated MCS and within about $500 \mathrm{~m}$ of the altitude of the turbulence encounter. Notwithstanding the fact that turbulence and the convection that generated it has low predictability, the level of agreement between the simulations and the observations is suggestive that the simulation is reproducing the mechanisms responsible for the severe turbulence encountered during this event. Thus, the results presented in this study show that the observed case of near-cloud turbulence may have been 
associated with a breaking convectively generated gravity wave that propagates into an environment that has already been destabilized by the mesoscale upper-level storm outflow. The localized nature of this particular case and the turbulence encounter would make it difficult to predict, but highlights the importance of small-scale and mesoscale process in nearcloud turbulence encounters.

Acknowledgments. DZR was supported by the Australian Research Council's (ARC) Centre of Excellence for Climate System Science (CE110001028). TPL was supported by the ARC Centre of Excellence for Climate Extremes (CE170100023). Computational resources were provided by the National Computational Infrastructure (NCI) facility in Canberra, Australia. We thank Dave Johnson (NCAR) for assistance with Fig. 1, and two anonymous reviewers for their comments on the manuscript.

\section{REFERENCES}

Abarbanel, H. D. I., D. D. Holm, J. E. Marsden, and T. Ratiu, 1984: Richardson number criterion for the nonlinear stability of three-dimensional stratified flow. Phys. Rev. Lett., 52, 2352-2355, https://doi.org/10.1103/PhysRevLett.52.2352.

Benjamin, S. G., and Coauthors, 2004: An hourly assimilationforecast cycle: The RUC. Mon. Wea. Rev., 132, 495-518, https://doi.org/10.1175/1520-0493(2004)132<0495:AHACTR> 2.0.CO;2.

Carbone, R. E., J. D. Tuttle, D. A. Ahijevych, and S. B. Trier, 2002: Inferences of predictability associated with warm season precipitation episodes. J. Atmos. Sci., 59, 2033-2056, https://doi.org/10.1175/1520-0469(2002)059<2033:IOPAWW> 2.0.CO;2.

Chou, M.-D., and M. J. Suarez, 1994: An efficient thermal infrared radiation parameterization for use in general circulation models. NASA Tech. Memo. 104606, NASA, 85 pp.

Clark, T. L., and W. R. Peltier, 1984: Critical level reflection and the resonant growth of nonlinear mountain waves. J. Atmos. Sci., 41, 3122-3134, https://doi.org/10.1175/1520-0469(1984) 041<3122:CLRATR $>2.0 . \mathrm{CO} ; 2$.

Cornman, L. B., C. S. Morse, and G. Cunning, 1995: Real-time estimation of atmospheric turbulence severity from in-situ aircraft measurements. J. Aircr., 32, 171-177, https://doi.org/ 10.2514/3.46697.

Duda, J. D., and W. A. Gallus, 2013: The impact of large-scale forcing on skill of simulated convective initiation and upscale evolution with convection-allowing grid spacings in the WRF. Wea. Forecasting, 28, 994-1018, https://doi.org/10.1175/ WAF-D-13-00005.1.

Ek, M. B., K. Mitchell, Y. Lin, E. Rogers, P. Grunmann, V. Koren, G. Gayno, and J. D. Tarpley, 2003: Implementation of Noah land surface model advances in the National Centers for Environmental Prediction operational mesoscale Eta model. J. Geophys. Res., 108, 8851, https://doi.org/10.1029/ 2002JD003296.

Fovell, R. G., D. Durran, and J. R. Holton, 1992: Numerical simulations of convectively generated stratospheric gravity waves. J. Atmos. Sci., 49, 1427-1442, https://doi.org/10.1175/ 1520-0469(1992)049<1427:NSOCGS > 2.0.CO; 2 .

—, R. D. Sharman, and S. B. Trier, 2007: A case study of convectively-induced clear air turbulence. 12th Conf. on Mesoscale Processes, Waterville Valley, NH, Amer. Meteor. Soc., 13.4, https://ams.confex.com/ams/12meso/techprogram/ paper_126190.htm.

Fritsch, J. M., and R. A. Maddox, 1981: Convectively driven mesoscale weather systems aloft. Part I: Observations. J. Appl. Meteor., 20, 9-19, https://doi.org/10.1175/1520-0450(1981) $020<0009$ :CDMWSA $>2.0$. CO;2.

_, R. J. Kane, and C. R. Chelius, 1986: The contribution of mesoscale convective weather systems to the warm-season precipitation in the United States. J. Climate Appl. Meteor., 25, 1333-1345, https://doi.org/10.1175/1520-0450(1986) 025<1333:TCOMCW>2.0.CO; 2 .

Fujita, T., 1955: Results of detailed synoptic studies of squall lines. Tellus, 7, 405-436, https://doi.org/10.3402/tellusa.v7i4.8920.

Grabowski, W. W., and T. L. Clark, 1991: Cloud-environment interface instability: Rising thermal calculations in two spatial dimensions. J. Atmos. Sci., 48, 527-546, https://doi.org/10.1175/ 1520-0469(1991)048<0527:CIIRTC > 2.0.CO;2.

Houze, R. A., 1989: Observed structure of mesoscale convective systems and implications for large-scale heating. Quart. J. Roy. Meteor. Soc., 115, 425-461, https://doi.org/10.1002/ qj. 49711548702 .

International Civil Aviation Organization, 2007: Meteorological service for international air navigation: Annex 3 to the convention on international civil aviation. Tech. Rep., $187 \mathrm{pp}$.

Janjić, Z. I., 2002: Nonsingular implementation of the MellorYamada level 2.5 scheme in the NCEP Meso model. NCEP Office Note 437, $61 \mathrm{pp}$.

Kain, J. S., 2004: The Kain-Fritsch convective parameterization: An update. J. Appl. Meteor., 43, 170-181, https://doi.org/ 10.1175/1520-0450(2004)043<0170:TKCPAU>2.0.CO;2.

Kaplan, M. L., A. W. Huffman, K. M. Lux, J. D. Cetola, J. J. Charney, A. J. Riordan, Y.-L. Lin, and K. T. Waight III, 2005: Characterizing the severe turbulence environments associated with commercial aviation accidents. Part 2: Hydrostatic mesoscale numerical simulations of supergradient wind flow and streamwise ageostrophic frontogenesis. Meteor. Atmos. Phys., 88, 153-173, https://doi.org/10.1007/s00703-004-0079-6.

Kim, J.-H., and H.-Y. Chun, 2010: A numerical study of clear-air turbulence (CAT) encounters over South Korea on 2 April 2007. J. Appl. Meteor. Climatol., 49, 2381-2403, https://doi.org/ 10.1175/2010JAMC2449.1.

— , and - 2011: Statistics and possible sources of aviation turbulence over South Korea. J. Appl. Meteor. Climatol., 50, 311-324, https://doi.org/10.1175/2010JAMC2492.1.

- , and - 2012: A numerical simulation of convectively induced turbulence above deep convection. J. Appl. Meteor. Climatol., 51, 1180-1200, https://doi.org/10.1175/JAMC-D11-0140.1.

,,-- R. D. Sharman, and S. B. Trier, 2014: The role of vertical shear on aviation turbulence within cirrus bands of a simulated western Pacific cyclone. Mon. Wea. Rev., 142, 27942813, https://doi.org/10.1175/MWR-D-14-00008.1.

Klemp, J. B., and D. R. Lilly, 1975: The dynamics of wave-induced downslope winds. J. Atmos. Sci., 32, 320-339, https://doi.org/ 10.1175/1520-0469(1975)032<0320:TDOWID >2.0.CO;2.

Knox, J. A., A. S. Bachmeier, W. M. Carter, J. E. Tarantino, L. C. Paulik, E. N. Wilson, G. S. Bechdol, and M. J. Mays, 2010: Transverse cirrus bands in weather systems: A grand tour of 
an enduring enigma. Weather, 65, 35-41, https://doi.org/ 10.1002/wea.417.

Lane, T. P., and R. D. Sharman, 2006: Gravity wave breaking, secondary wave generation, and mixing above deep convection in a three-dimensional cloud model. Geophys. Res. Lett., 33, L23813, https://doi.org/10.1029/2006GL027988.

$\longrightarrow$, and - 2008: Some influences of background flow conditions on the generation of turbulence due to gravity wave breaking above deep convection. J. Appl. Meteor. Climatol., 47, 2777-2796, https://doi.org/10.1175/2008JAMC1787.1.

$\ldots$, and _ 2014: Intensity of thunderstorm-generated turbulence revealed by large-eddy simulation. Geophys. Res. Lett., 41, 2221-2227, https://doi.org/10.1002/2014GL059299.

,,-- T. L. Clark, and H. M. Hsu, 2003: An investigation of turbulence generation mechanisms above deep convection. J. Atmos. Sci., 60, 1297-1321, https://doi.org/10.1175/ 1520-0469(2003)60<1297:AIOTGM > 2.0.CO;2.

$\longrightarrow,-$, S. B. Trier, R. G. Fovell, and J. K. Williams, 2012: Recent advances in the understanding of near-cloud turbulence. Bull. Amer. Meteor. Soc., 93, 499-515, https://doi.org/ 10.1175/BAMS-D-11-00062.1.

Lenz, A., K. M. Bedka, W. F. Feltz, and S. A. Ackerman, 2009: Convectively induced transverse band signatures in satellite imagery. Wea. Forecasting, 24, 1362-1373, https://doi.org/ 10.1175/2009WAF2222285.1.

Lester, P. F., 1994: Turbulence: A New Perspective for Pilots. Jeppesen Sanderson, 290 pp.

Mlawer, E. J., S. J. Taubman, P. D. Brown, M. J. Iacono, and S. A. Clough, 1997: Radiative transfer for inhomogeneous atmospheres: RRTM, a validated correlated-k model for the longwave. J. Geophys. Res., 102, 16 663-16 682, https://doi.org/ 10.1029/97JD00237.

Nappo, C. J., 2002: An Introduction to Atmospheric Gravity Waves. Academic Press, 276 pp.

Pantley, K. C., and P. F. Lester, 1990: Observations of severe turbulence near thunderstorm tops. J. Appl. Meteor. Climatol., 29, 1171-1179, https://doi.org/10.1175/1520-0450(1990) $029<1171$ :OOSTNT $>2.0 . \mathrm{CO} ; 2$.

Peltier, W. R., and T. L. Clark, 1979: The evolution and stability of finite-amplitude mountain waves. Part II: Surface wave drag and severe downslope windstorms. J. Atmos. Sci., 36, 1498-1529, https://doi.org/10.1175/1520-0469(1979) 036<1498:TEASOF $>2.0 . \mathrm{CO} ; 2$.

- , and - 1983: Nonlinear mountain waves in two and three spatial dimensions. Quart. J. Roy. Meteor. Soc., 109, 527-548, https://doi.org/10.1002/qj.49710946106.

Prophet, D. T., 1970: Vertical extent of turbulence in clear air above the tops of thunderstorms. J. Appl. Meteor., 9, 320-321, https://doi.org/10.1175/1520-0450(1970)009<0320:VEOTIC > 2.0.CO;2.

Sharman, R. D., C. Tebaldi, G. Wiener, and J. Wolff, 2006: An integrated approach to mid- and upper-level turbulence forecasting. Wea. Forecasting, 21, 268-287, https://doi.org/ 10.1175/WAF924.1.

, L. B. Cornman, G. Meymaris, J. Pearson, and T. Farrar, 2014: Description and derived climatologies of automated in situ eddy-dissipation-rate reports of atmospheric turbulence. J. Appl. Meteor. Climatol., 53, 1416-1432, https:// doi.org/10.1175/JAMC-D-13-0329.1.

Skamarock, W. C., and Coauthors, 2008: A description of the Advanced Research WRF version 3. NCAR Tech. Note NCAR/TN-475+STR, 113 pp., https://doi.org/10.5065/ D68S4MVH.

Song, I.-S., H.-Y. Chun, and T. P. Lane, 2003: Generation mechanisms of convectively forced internal gravity waves and their propagation to the stratosphere. J. Atmos. Sci., 60, 1960-1980, https://doi.org/10.1175/1520-0469(2003)060<1960:GMOCFI > 2.0.CO;2.

Squitieri, B. J., and W. A. Gallus, 2016: WRF forecasts of Great Plains nocturnal low-level jet-driven MCSS. Part II: Differences between strongly and weakly forced low-level jet environments. Wea. Forecasting, 31, 1491-1510, https://doi.org/ 10.1175/WAF-D-15-0150.1.

Thompson, G., P. R. Field, R. M. Rasmussen, and W. D. Hall, 2008: Explicit forecasts of winter precipitation using an improved bulk microphysics scheme. Part II: Implementation of a new snow parameterization. Mon. Wea. Rev., 136, 5095-5115, https://doi.org/10.1175/2008MWR2387.1.

Trier, S. B., and R. D. Sharman, 2009: Convection-permitting simulations of the environment supporting widespread turbulence within the upper-level outflow of a mesoscale convective system. Mon. Wea. Rev., 137, 1972-1990, https:// doi.org/10.1175/2008MWR2770.1.

_ , and -2016 : Mechanisms influencing cirrus banding and aviation turbulence near a convectively enhanced upper-level jet stream. Mon. Wea. Rev., 144, 3003-3027, https://doi.org/ 10.1175/MWR-D-16-0094.1.

_ C. A. Davis, D. A. Ahijevych, M. L. Weisman, and G. Bryan, 2006: Mechanisms supporting long-lived episodes of propagating nocturnal convection within a 7-day WRF Model simulation. J. Atmos. Sci., 63, 2437-2461, https://doi.org/10.1175/ JAS3768.1.

— , R. D. Sharman, R. G. Fovell, and R. G. Frehlich, 2010: Numerical simulation of radial cloud bands within the upper-level outflow of an observed mesoscale convective system. J. Atmos. Sci., 67, 2990-2999, https://doi.org/10.1175/2010JAS3531.1.

,-- , and T. P. Lane, 2012: Influences of moist convection on a cold-season outbreak of clear-air turbulence (CAT). Mon. Wea. Rev., 140, 2477-2496, https://doi.org/10.1175/ MWR-D-11-00353.1.

Williams, J. K., J. K. Wolff, A. Cotter, and R. D. Sharman, 2006: Evaluating effectiveness of the FAA's CIT avoidance guidelines. 12th Conf. on Aviation Range and Aerospace Meteorology, Atlanta, GA, Amer. Meteor. Soc., P1.6, https://ams.confex.com/ ams/Annual2006/techprogram/paper_103420.htm.

Wolff, J. K., and R. D. Sharman, 2008: Climatology of upper-level turbulence over the contiguous United States. J. Appl. Meteor. Climatol., 47, 2198-2214, https://doi.org/10.1175/2008JAMC1799.1.

Zovko-Rajak, D., and T. P. Lane, 2014: The generation of nearcloud turbulence in idealized simulations. J. Atmos. Sci., $\mathbf{7 1}$, 2430-2451, https://doi.org/10.1175/JAS-D-13-0346.1. 